\title{
Late Jurassic theropod dinosaur bones from the Langenberg Quarry (Lower Saxony, Germany) provide evidence for several theropod lineages in the central European archipelago
}

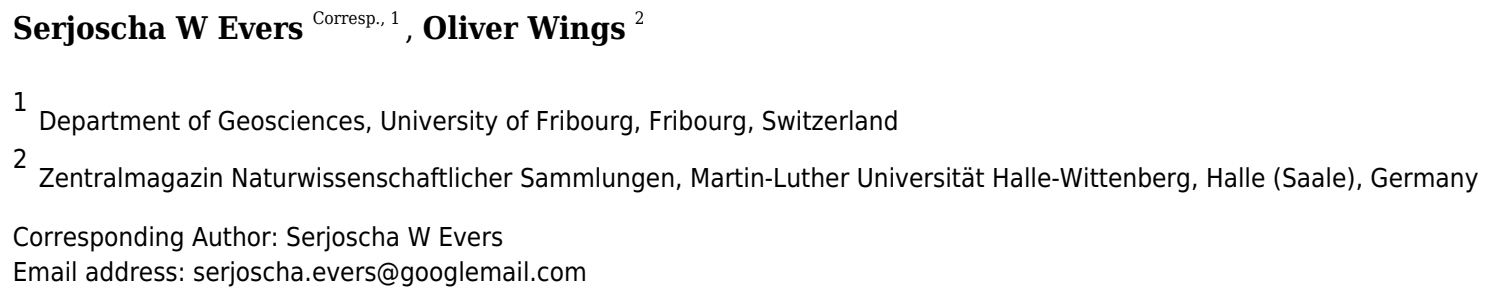

Marine limestones and marls in the Langenberg Quarry provide unique insights into a Late Jurassic island ecosystem in central Europe. The beds yield a varied assemblage of terrestrial vertebrates including extremely rare bones from theropod dinosaurs, which we describe here for the first time. All of the theropod bones belong to relatively small individuals but represent a wide taxonomic range. The material comprises an allosauroid small pedal ungual and pedal phalanx, a ceratosaurian anterior chevron, a left fibula of a megalosauroid, and a distal caudal vertebra of a tetanuran. Additionally, a small pedal phalanx III-1 and the proximal part of a small right fibula can be assigned to indeterminate theropods. The ontogenetic stages of the material are currently unknown, although the assignment of some of the bones to juvenile individuals is plausible. The finds confirm the presence of several taxa of theropod dinosaurs in the archipelago and add to our growing understanding of theropod diversity and evolution during the Late Jurassic of Europe. 


\section{Late Jurassic theropod dinosaur bones from the}

2 Langenberg Quarry (Lower Saxony, Germany) provide

3 evidence for several theropod lineages in the central

4 European archipelago

5

6

7

8

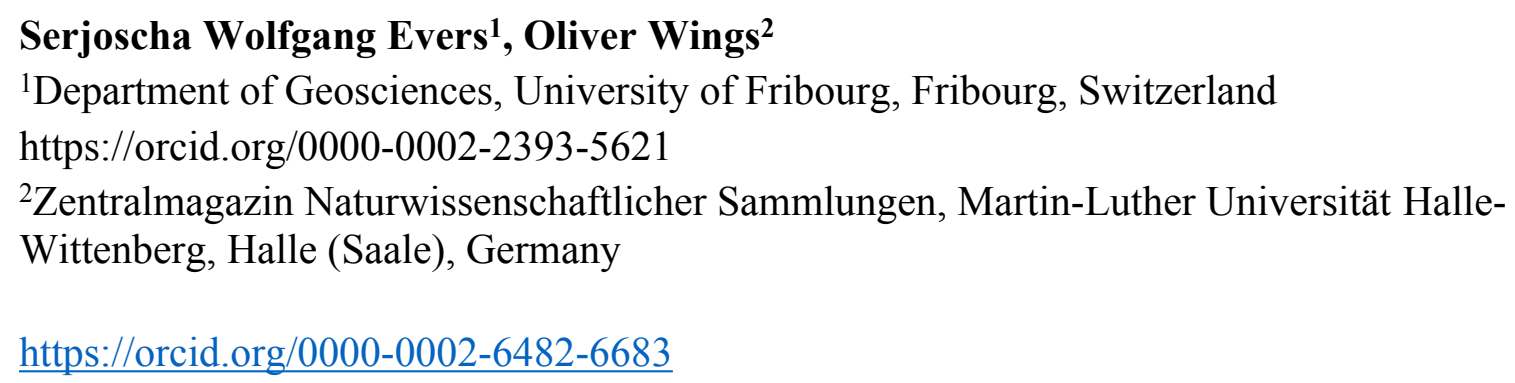

Corresponding author:

Serjoscha Evers

Department of Geosciences, University of Fribourg, Chemin du Musèe 4, 1700 Fribourg, Switzerland Email address: serjoscha.evers@googlemail.com

\section{Abstract}

Marine limestones and marls in the Langenberg Quarry provide unique insights into a Late Jurassic island ecosystem in central Europe. The beds yield a varied assemblage of terrestrial vertebrates including extremely rare bones from theropod dinosaurs, which we describe here for the first time. All of the theropod bones belong to relatively small individuals but represent a wide taxonomic range. The material comprises an allosauroid small pedal ungual and pedal phalanx, a ceratosaurian anterior chevron, a left fibula of a megalosauroid, and a distal caudal vertebra of a tetanuran. Additionally, a small pedal phalanx III-1 and the proximal part of a small right fibula can be assigned to indeterminate theropods. The ontogenetic stages of the material are currently unknown, although the assignment of some of the bones to juvenile individuals is plausible. The finds confirm the presence of several taxa of theropod dinosaurs in the archipelago and add to our growing understanding of theropod diversity and evolution during the Late Jurassic of Europe.

\section{Introduction}

Late Jurassic terrestrial sediments have seen a long history of fossil exploration (e.g. Close et al., 2018; Tennant, Chiarenza \& Baron, 2018), which led to the discovery of an amazingly high 
number of dinosaur bearing formations (e.g. McAllister Rees et al., 2004). Despite the great dinosaur diversity known from that age (e.g. Lloyd et al., 2008; Barrett, McGowan \& Page, 2009; Mannion et al., 2011), regional gaps in our knowledge of Late Jurassic dinosaur faunas still do exist. For example, most of Northern Germany was submerged during the Late Jurassic, resulting in an almost exclusively marine fossil record (Ziegler, 1990). A very rare exception is the Langenberg Quarry at the northern rim of the Harz Mountains where a variety of terrestrial vertebrates have been washed into the marine depositional environment from a nearby island (e.g. Sander et al., 2006, Wings \& Sander, 2012, Wings, 2015). The diverse tetrapod fauna of the Langenberg Quarry is particularly famous for the occurrence of the dwarf sauropod Europasaurus holgeri, but also includes mammals, pterosaurs, turtles, crocodylians, and squamates (e.g., Wings \& Sander, 2012; Wings, 2015). The theropod bones from the Langenberg Quarry have so far received limited attention (but see Gerke \& Wings, 2016), because of the general rarity and incompleteness of theropod material. Here, we describe the exceptionally rare theropod bones from that locality for the first time. Although much of the fragmentary material can only be classified on higher taxonomic levels, the new occurrences reported herein add to our understanding of the regional tetrapod fauna and to theropod diversity in general.

\section{Locality, Geology and Stratigraphy}

The Langenberg Quarry near the town of Goslar, Lower Saxony, northern Germany (Figure 1) is a classic and well-studied locality exposing large sections of Late Jurassic shallow marine strata (Fischer 1991; Lotze 1968; Pape 1970; Zuo et al. 2017). The layers consist of impure carbonates grading into marls. Tilted to a nearly vertical, slightly overturned position, the beds are quarried along strike, exposing them only in cross section and not along bedding planes. Sediment composition and invertebrate faunal content record changes in water depth and clear brackish influences, but there is no evidence of subaerial exposure (Lotze 1968; Pape 1970). The well dated sediments in the quarry range from late Oxfordian to late Kimmeridgian in age (Fischer 1991; Lotze 1968; Pape 1970; Zuo et al. 2017). After the stratigraphic subdivision of Fischer (1991), most of the terrestrial vertebrate remains (including the sauropod dinosaur Europasaurus holgeri and all theropod bones) were found in bed 83, not in bed 93 as erroneously stated in some publications (Carballido \& Sander 2013; Marpmann et al. 2014; Sander et al. 2006). This bed is a light grey-greenish marly limestone. It has been assigned to the "Mittleres Kimmeridge", a northwest-German equivalent to the lower part of the upper Kimmeridgian of the international chronostratigraphic time scale (Lallensack et al. 2015; Schweigert 1999). During the Late Jurassic, the Langenberg Quarry was located in the Lower Saxony Basin that covered much of northern Germany and that was surrounded by several paleo-islands (Ziegler 1990), the source of the clastic components in the sediment. Fossil Vertebrates from the Langenberg Quarry

The Langenberg Quarry is the only locality where the abundant and exquisitely threedimensionally preserved material of the dwarfed sauropod dinosaur Europasaurus holgeri has been found (Carballido \& Sander 2013; Marpmann et al. 2014; Sander et al. 2006). The quarry 
77 also yielded a number of isolated teeth which belong to several different groups of theropod 78 dinosaurs (Gerke \& Wings 2016) as well as natural track casts of large theropods (Lallensack et 79 al. 2015).

80 Beds 83 and 73 also have produced a variety of non-dinosaurian vertebrate remains. Among 81 them are the only known Jurassic mammals from Germany, the pinheirodontid multituberculate 82 Teutonodon langenbergensis (Martin et al., 2016), the paulchoffatiid multituberculate 83 Cimbriodon multituberculatus (Martin et al., 2019), and the large morganucodontan 84 mammaliaform Storchodon cingulatus (Martin et al., in press). Additionally, a three85 dimensionally preserved articulated skeleton of a small pterosaur (Fastnacht 2005), teeth and 86 skeletons of the small non-marine atoposaurid crocodilian Knoetschkesuchus langenbergensis 87 (Schwarz et al. 2017), various remains of marine crocodylians (Karl et al., 2006; 2008) and the 88 partial skeleton of a paramacellodid lizard (Richter et al. 2013) have been reported. Diverse marine turtle material (including several skulls) comprises cf. Thalassemys sp., Plesiochelys sp., and possibly a new taxon (Jansen \& Klein 2014). Microvertebrate remains from the Langenberg yield beside many reptilian teeth (Wings, pers. obs.) a diverse fish fauna represented mainly by isolated teeth of marine chondrichthyans and osteichthyans (Mudroch 2001; Mudroch \& Thies 1996; Thies 1995).

\section{Taphonomy}

95 Almost all of the fossil material from terrestrial vertebrates (including all material described herein) was recovered after regular blasting operations in the quarry. Despite the large number of bones and teeth known from the sauropod Europasaurus holgeri, the general distribution of bones and teeth in bed 83 is rare. All of the extremely rare theropod bones were found intermingled with the mostly disarticulated $E$. holgeri material. All skeletal remains were accumulated in certain areas, probably lenses or channels. The bone-bearing sections of bed 83 were usually $30-50 \mathrm{~cm}$ thick and contained in all bone-rich areas a large number of well-rounded micritic intraclasts. The combination of bone material and intraclasts is also important for recognizing blocks of this specific layer in the quarry heap after the blasting. Because the blocks were not found in situ, it remains possible, although very unlikely, that the finds come from another bed nearby. In any case, they clearly belong to the lower part of the upper

106 Kimmeridgian.

107

108

\section{Abbreviations}

109 BSPG Bayerische Staatssammlung für Paläontologie und Geologie, Munich, Germany

110 BYU Brigham Young University, Provo, Utah, USA

$111 \mathrm{DfmMh} / \mathrm{FV}$ Dinosaurier-Freilichtmuseum Münchehagen/Verein zur Förderung der

112 niedersächsischen Paläontologie, Rehburg-Loccum, Germany

113 IVPP Institute of Vertebrate Paleomntology and Paleoanthropology, Beijing, China

114 JM SCHA Juramuseum Eichstätt, Eichstätt, Germany

115 MNN Museé National du Niger, Niamey, Niger 
116 OUMNH Oxford University Museum of Natural History, Oxford, UK

117 SMNS Staatliches Museum für Naturkunde Stuttgart, Stuttgart, Germany

118 UC University of Chicago, Chicago, Illinois, USA

119 UMNH Utah Museum of Natural History, Salt Lake City, Utah, USA

120

121 Materials and Methods

122 The present work is based on several isolated bones, which have been morphologically examined

123 by the authors. Comparisons have been made on the basis of first hand observation on relevant

124 material by one of us (SWE), as well as literature comparisons.

125

126

\section{Results}

127

128

129

130

131

132

133

134

135

136

137

138

139

140

141

142

143

144

145

146

147

148

149

150

151

152

153

154

In the following section, we describe each specimen, provide its systematic identification, and justify the latter in a remarks section by comparative notes.

Dinosauria Owen, 1842

Theropoda Marsh, 1881

Tetanurae Gauthier, 1986

Avetheropoda Paul, 1988

Allosauroidea (Marsh, 1878) Currie \& Zhao, 1993

Material: DfMMh/FV1/19, small pedal ungual (Figure 2A-D).

Description: DfMMh/FV1/19 is an ungual that measures $23 \mathrm{~mm}$ in a straight line from the extensor tubercle to the distal tip. DfMMh/FV1/19 is relatively slender, and ventrally only moderately broader than dorsally. The ungual has a transversely expanded proximal surface for the articulation with the preceding phalanx, and a moderately recurved body that extends distally into a sharp tip.

The proximal surface of DfMMh/FV1/19 is vaguely triangular in shape, transversely narrow, and dorsoventrally taller than wide. Its maximal height is $8 \mathrm{~mm}$, and the maximal width is $6 \mathrm{~mm}$. The proximal surface is slightly damaged at the ventral rim, but the overall shape is discernible as only the surface of the element seems to be superficially broken. The margin around the proximal surface is developed as a salient rim ventrally to the extensor tubercle. While the surface of the ungual is generally smooth, the surface around this proximal rim is roughened. The extensor tubercle forms a short proximally overhanging tip at the dorsal margin of the proximal surface, and bears weak longitudinal striations on its dorsal surface (Figure 2A-D). The latero- and medioventral edges of the proximal surface form protruding flanges, expanding the ventral part of the proximal surface transversely in relation to the dorsal margin (Figure $2 \mathrm{~B}$ ). The articulation facet for the preceding phalanx on the proximal surface is dorsoventrally only weakly concave and lacks a distinct vertical median ridge, although the central portion of the facet is slightly raised in comparison to the parts of the facet near the outer margins. The dorsolateral and dorsomedial portions of the proximal facet are gently deepened, indicating that the distal surface of the preceding phalanx was slightly ginglymoid. 
155 The body of the ungual is ventrally curved, and tapers to a sharp distal tip (Figure 2C-D). The

156 dorsal surface of the body of the ungual is continuous with the surface of the extensor tubercle.

157 This surface is transversely strongly convex and smooth. On the lateral and medial side, the body

158 of the ungual is separated from the proximal surface by a low depression, which gives the claw a

159 slightly constricted morphology just distal to the proximal articulation.

160 Distal to this constriction, the ventral surface of the body of the ungual is weakly broader than

161 the dorsal surface. The ventral surface is also slightly less ventrally curved than the dorsal

162 margin, and is transversely almost flat for most of its length, and just slightly transversely

163 convex near the tip pf the ungual. In the proximal part, distal to the proximal facet and separated

164 from its margin by a shallow transverse groove, the ventral surface of the claw exhibits a small

165 mount-like structure, the flexor tubercle (Figure 2B-D). As parts of the ventral surface of the

166 claw are damaged toward the proximal articulation, the distal and left side of the flexor tubercle

167 cannot be described. On the right side, however, there seems to be a small oblique groove or

169 elongate depression that separates the flexor tubercle from the margin of the proximal facet. The lateral and medial surface of the ungual are each incised by a deep groove (Figure 2C-D), which separates the body of the ungual into a broadened ventral part and a dorsal part. The collateral grooves parallel the ventral margin of the claw, and are therefore ventrally concavely rounded. At its proximal end, each groove merges with the medial and lateral depression, respectively. Each collateral groove starts proximally on a central position on the lateral and medial surface, respectively, but continues distally to a slightly dorsoventrally higher position, so that the broad ventral part of the claw is relatively prominent distally. Remarks: Precise identification of DfMMh/FV1/19 is difficult, as unguals are generally not described in detail in the literature. We tentatively identify DfMMh/FV1/19 as belonging to a theropod dinosaur. Unfortunately, unguals of alternative taxa, such as crocodiles, lizards, and testudinids, all groups for which fossils have been found and described from the Langenberg Quarry (Thies, Windorf \& Mudroch, 1997; Karl et al., 2006; Karl et al., 2008; Jansen \& Klein, 2013; Richter et al., 2013; Schwarz et al., 2017), are even less described in the literature than theropod unguals, so that the following comments are largely based on personal observations. Testudinid taxa that appear in the Lower Saxony Basin, including the Langenberg Quarry (e.g. Jansen \& Klein, 2013), and that are common more generally in coastal and shallow marine settings in the Late Jurassic belong to an enigmatic array of eucryptodiran taxa known as eurysternids, plesiochelyids, and thalassemydids (Anquetin, Püntener \& Joyce, 2017; Evers \& Benson, 2018). Eurysternids, a eucryptodiran group of Late Jurassic, secondarily marine turtles are known from many relatively complete specimens that often include manual and pedal unguals. Eurysternids generally have manual and pedal unguals that are more robust, i.e. anteroposteriorly short but transversely broad (e.g. Eurysternum wagleri BSPG AS I 921, BSPG 1600 VIII 43, SMNS 59731; Solnhofia parsoni JM SCHA 70; Joyce, 2000; Anquetin \& Joyce, 2014). $\mathrm{DfMMh} / \mathrm{FV} 1 / 19$ exhibits some features that are comparable to claws of theropod dinosaurs. 
195 morphology. Pedal unguals usually exhibit a weaker degree of curvature, are transversely

196 broader and ventrally flatter than their manual counterparts. They also have less strongly

197 developed extensor and flexor tubercles, and often lack a distinct median vertical ridge on the

198 proximal articulation facet (e.g. Allosaurus fragilis: Madsen, 1976; Eustreptospondylus

199 oxoniensis: Sadleir et al., 2008; Australovenator wintonensis: Hocknull et al., 2009). In manual

200 unguals, the median ridge is generally well developed, and separates a medial and lateral surface

201 for the respective cotyles on the strongly ginglymoid distal articulation surfaces of penultimate

202 manual phalanges (e.g. Australovenator wintonensis: White et al., 2012). These surfaces are

203 dorsoventrally usually quite tall, and the entire proximal surface is laterally and medially not

204 much expanded in respect to the distal part of the claw so that manual unguals appear laterally

205 compressed. Additionally, the flexor tubercle is pronounced in manual unguals (Rauhut, 2003a).

206 The features described above for DfMMh/FV1/19 are congruent with the generalised features of

207 theropod pedal unguals, and thus we interpret DfMMh/FV1/19 to represent such an element.

208 However, it remains unclear if DfMMh/FV1/19 represents a right or left element, and we are

209 also uncertain about the digit identity of DfMMh/FV1/19.

210 Isolated teeth of Late Jurassic theropod dinosaurs from the Lower Saxony Basin in Northern

211 Germany, including material from the Langenberg Quarry, have been identified by multivariate

212 and cladistics analyses as belonging to basal Tyrannosauroidea, Allosauroidea, Megalosauroidea,

213 and Ceratosauria (Gerke \& Wings, 2016). These taxa therefore provide potential comparative

214 clues about the taxonomic identification of DfMMh/FV1/19.

215 Pedal unguals of non-abelisaurid ceratosaurs, such as Limusaurus inextribacilis (IVPP P 15923),

216 are more robust, less recurved, and dorsoventrally more flattened as well as transversely broader

217 than seen in DfMMh/FV1/19. DfMMh/FV1/19 also does not compare well with abelisaurid

218 ceratosaurs. Pedal unguals reported for abelisaurids commonly show a broad triangular

219 depression on the ventral surface (e.g. Majungasaurus crenatissimus: Carrano, 2007;

220 Eoabelisaurus mefi: Pol \& Rauhut, 2012), and at least some forms have a pair of collateral

221

222 grooves on either side of the claw body (e.g. Masiakasaurus knopfleri: Carrano, Sampson \&

223 Forster, 2002). All of these features are absent in DfMMh/FV1/19.

224 Pedal unguals of basal tyrannosauroids also differ substantially from DfMMh/FV1/19. The

225 proceratosaurid tyrannosauroid Guanlong wucaii (IVPP 14532) has relatively large extensor tubercles, collateral grooves that deepen dorsoventrally toward the proximal end of the ungual,

226 and proximal articulations that are much more strongly concave than seen in DfMMh/FV1/19. In

227

228 the basal tyrannosauroid Dilong paradoxus (IVPP V 11579), the pedal unguals are proximally dorsoventrally much deeper than in DfMMh/FV1/19, right and left sub-facets are separated by a

229

230 moderately strong median ridge, and flexor tubercles are much more prominent, significantly expanding the depth of the proximal part of the unguals ventrally.

231 In megalosauroid theropods, pedal unguals are general more robust that seen in DfMMh/FV1/19.

232 For instance, Eustreptospondylus oxoniensis has a preserved pedal ungual that is transversely

233 broader in regard to DfMMh/FV1/19 both at the dorsal and ventral margins of the ungual body 
234 (OUMNH.J 13558: Sadleir et al., 2008). Additionally, the extensor tubercle is more prominent

235

236

237

238

239

240

241

242

243

244

245

246

247

248

249

250

251

252

253

254

255

256

257

258

259

260

261

262

263

264

265

266

267

268

269

270

271

272

273 and the proximal articulations facet is oval rather than triangular.

$\mathrm{DfMMh} / \mathrm{FV} 1 / 19$ has superficial similarities to Allosaurus fragilis, in that the degree of curvature is similar, weak flexor tubercles and relatively flat ventral surfaces are present, and right and left sub-facets on the proximal articulation are only weakly differentiated (e.g. UMNH VP 5355, 5365, 5368, 6771). However, in Allosaurus fragilis pedal unguals are generally dorsoventrally higher than in DfMMh/FV1/19, have slightly more expanded extensor tubercles, somewhat more laterally compressed proximal articulation facets, and the collateral grooves are positioned more dorsally on the claw body.

$\mathrm{DfMMh} / \mathrm{FV} 1 / 19$ is closest in both overall similarity as well as detailed aspects of morphology to material described for the neovenatorid Australovenator wintonensis (Hocknull et al., 2009; White et al., 2012). It should be noted that the unguals of Australovenator wintonensis are likely the best described unguals for any theropod dinosaur, as all ungual elements are described separately, figured, and 3D models that were created on the basis of CT scans were made available (White et al. 2012). The pedal unguals of the fourth digit (IV-5) of Australovenator wintonensis but also Neovenator salerii (Brusatte, Benson \& Hutt, 2008) are very similar to $\mathrm{DfMMh/FV1/19:} \mathrm{the} \mathrm{respective} \mathrm{specimens} \mathrm{share} \mathrm{a} \mathrm{similar} \mathrm{degree} \mathrm{of} \mathrm{curvature;} \mathrm{a} \mathrm{relatively} \mathrm{flat}$ ventral surface; a short extensor tubercle and rim around the proximal articulation facet; a gently concave facet with incomplete separation of medial and lateral sub-facets by a shallow central tubercle; a mediolaterally slightly constricted area between the proximal surface and the body of the claw; and shallow a depression to either side of the flexor tubercle. However, there are also important differences to neovenatorid theropods: Australovenator wintonensis and Neovenator salerii have a more prominent extensor tubercle than DfMMh/FV1/19 and a ventral part of the claw body that is transversely broader in relation to the dorsal portion of the claw. Additionally, the rim around the articular facet is much narrower in Australovenator wintonensis and Neovenator salerii. DfMMh/FV1/19 is also similar to the pedal ungual of the second digit (II-3) of Australovenator wintonensis. In this element, the ventral surface of the claw is less expanded transversely than in IV-5, which is more like the morphology of DfMMh/FV1/19. However, in II-3, the collateral grooves on the claw body are less deep than in both the IV-5 of Australovenator wintonensis or DfMMh/FV1/19. The pedal ungual of the first digit (I-2) of Australovenator does not match the morphology of DfMMh/FV1/19 well, as this element has a more prominent extensor tubercle, and a dorsoventrally high ovoid proximal surface as well as only faintly developed collateral grooves. The ungual of the third digit (III-4) of Australovenator wintonensis seems proximally distorted, so that the degree of similarity to DfMMh/FV1/19 is harder to establish.

Based on these anatomical observations, a tentative identification of DfMMh/FV1/19 as a pedal ungual of a neovenatorid theropod seems plausible. However, several arguments cast doubt on this interpretation. For instance, DfMMh/FV1/19 is relatively small in general terms of neovenatorids, which commonly achieve body masses of more than one metric ton and femoral lengths of around $750 \mathrm{~mm}$ (e.g. Neovenator salerii; Benson et al., 2014), so that it is highly

Peer) reviewing PDF | (2019:11:43051:1:1:NEW 18 Dec 2019) 
274 likely that DfMMh/FV1/19 represents a juvenile, if it were a neovenatorid. Secondly, our

275

276

277

278

279

280

281

282

283

284

285

286

287

288

289

290

291

292

293

294

295

296

297

298

299

300

301

302

303

304

305

306

307

308

309

310

311

312

313

interpretation could be biased by the availablility of extremely detailed ungual descriptions for neovenatorid theropods. Additionally, a neoventorid interpretation would result in a substantial range extension for the clade, as neovenatorids are thought to have evolved during the Early Cretaceous (Benson, Carrano \& Brusatte, 2010). Basing a range extension into the Late Jurassic on our fragmentary remains seems problematic. Further and more complete material is needed to test the possible presence of neovenatorid theropods in Oker. Here, we stick with a more conservative approach and simply refer the specimen to Allosauroidea, as we are reasonably confident with this assignment given the fragmentary nature of the material.

Dinosauria Owen, 1842

Theropoda Marsh, 1881

Tetanurae Gauthier, 1986

Avetheropoda Paul, 1988

cf. Allosauroidea (Marsh, 1878) Currie \& Zhao, 1993

Material: DfMMh/FV/343, small pedal phalanx (Figure 2E-J).

Description: DfMMh/FV/343 is a small proximal pedal phalanx that measures $11 \mathrm{~mm}$ in length.

The proximal articular facet of the phalanx is $7 \mathrm{~mm}$ wide, narrows from ventral to dorsal and is 3 $\mathrm{mm}$ tall. Overall, the element is stout in dorsoventral view due to its relatively large width, but appears much more slender in lateral view due to its relatively short dorsoventral height. A small extensor turbercle is developed at the dorsal surface of the proximal end (Figure 2E, H). The phalangeal shaft of DfMMh/FV/343 is somewhat more slender than the articular ends of the element, and the ventral surface of the shaft is flattened. Proximally, a broad flexor fossa is welldeveloped (Figure 2F). The anterior end of the element is developed as a $6 \mathrm{~mm}$ wide trochlea that is not subdivided into distinct left and right cotylar facets (Figure 2J). Ligament pits are developed on each of the lateral cotyle surfaces. These pits are relatively deep on both sides in $\mathrm{DfMMh} / \mathrm{FV} / 343$, and do not occupy the entire lateral surface of the cotyles. On the dorsal surface, a distally placed extensor groove (for the following phalanx) is absent.

Remarks: Similarly to the pedal ungual, interpretation of DfMMh/FV/343 is complicated by the fact that the phalangeal morphology of many taxa occurring in the Langenberg Quarry is not well described. However, the general morphology of DfMMh/FV/343 is consistent with that of a pedal phalanx of a theropod dinosaur. The relatively broad overall shape of DfMMh/FV/343, as well as the presence of a singular proximal articulation facet that is not divided by a vertical ridge in subfacets or the presence of only moderately development extensor tubercles is generally typical for proximal pedal phalanges of theropods (e.g., Madsen, 1976). Although little has been explicitly published on pedal phalanx morphology for theropods, a few comparisons can be made, and which indicate potential allosauroid affinities of the material. For instance, the collateral ligament pits of DfMMh/FV/343 are deep but relatively small, as for instance in Australovenator wintonensis (White et al., 2012) and Allosaurus fragilis (Madsen, 1976), whereas the pits occupy the entire cotylar surface and are smore shallowly sloping, funnel like depressions in Eustreptospondylus oxoniensis (Sadleir, Barrett \& Powell, 2008). The absent

Peer) reviewing PDF | (2019:11:43051:1:1:NEW 18 Dec 2019) 
314 distal extensor grooves of DfMMh/FV/343 are unusual for allosauroids and theropods more

315 widely, but it should be noted that these grooves are usually weakest in proximal phalanges (e.g.

316 White et al., 2012)

$317 \mathrm{DfMMh} / \mathrm{FV} / 343$ was found in the same block of matrix as the pedal phalanx

$318 \mathrm{DfMMh} / \mathrm{FV} 1 / 19$, although not in articulation or particularly close association with it (pers.

319 comm., Nils Knötschke). Both specimens have are relatively small, with the ungual being

320 somewhat longer than the non-ungual phalanx. In neovenatorid theropods, unguals are equally

321 long or longer than more proximally positioned phalanges in the fourth digit (e.g. Brusatte,

322 Benson \& Hutt, 2008), which is consistent with one of the possibly identifications of the ungual.

323 Therefore, it is possible (but highly speculative) that both elements belong to the same

324 individual. Although we find some indications that the pedal phalanx could belong to a

325 neovenatorid, we more conservatively assign it to Allosauroidea.

326

327

328

329

330

331

Dinosauria Owen, 1842

Theropoda Marsh, 1881

cf. Ceratosauria Marsh, 1884

Material: DfMMh/FV/776, anterior chevron (Figure 3A-E).

Description: DfMMh/FV/776 is a chevron from an anterior position within the caudal vertebral series. The chevron consists of a well-preserved haemal arch and an incompletely preserved

332 haemal spine. The haemal spine is crushed in the distal third of its preserved length, and the

333

334 distal tip is broken and not preserved. The preserved parts of DfMMh/FV/776 measure c. 110 $\mathrm{mm}$.

335

The haemal arch consists of two lateral processes that border the haemal canal, and a proximal articular surface that is buttressed by the lateral processes. The lateral chevron processes and the haemal spine are angled strongly posteriorly in respect to the articulation surface (Figure 3B, D). The haemal canal is vaguely triangular and proximally broader than distally (Figure 3A, C). It measures $12 \mathrm{~mm}$ across its widest part, and is $16 \mathrm{~mm}$ high. The lateral processes are anteriorly expanded to convex flanges that expand the lateral wall of the haemal canal anteriorly. These flanges are relatively small, and form symmetrically rounded anterior margins (Figure 3B, D). A similar, yet much less prominent posterior expansion of the lateral processes is present. The articulation surface of DfMMh/FV/776 is anteroposteriorly narrow, measuring $11 \mathrm{~mm}$, and transversely broad, measuring $35 \mathrm{~mm}$. The articulation facet is not subdivided into anterior and posterior subfacets for the preceding and successive caudal vertebral articulations, but the topology of the surface is also not uniform (Figure 3E). Instead, the articulation surface is convexly rounded to either side laterally and concavely depressed centrally. The margin surrounding the articulation surface is gently elevated, which is particularly prominent on the posterior side.

The haemal spine is elongate and slender, and has approximately parallel anterior and posterior margins. It forms a straight process that is not posteriorly kinked or curved. The transverse (=mediolateral) width of the haemal spine decreases from $8 \mathrm{~mm}$ proximally, to $4 \mathrm{~mm}$ at its broken distal end. DfMMh/FV/776 has a low but prominent median keel on the anterior surface 
354 of the haemal spine (Figure 3A). The keel has a sharp margin and is deepest proximally, where it 355 forms a low anteriorly projecting flange. The proximal part of the posterior surface of the haemal 356 spine shows a broad groove, which is continuous with the posterior opening of the haemal canal. 357 This groove gets shallower distally and is replaced by a low median keel in the central parts of 358 the haemal spine. The posterior keel becomes more prominent distally, and develops to a ridge359 like posterior margin in the distal third of the preserved haemal spine length.

360 Remarks: DfMMh/FV/776 can be identified as an anterior chevron of a large theropod dinosaur, 361 because of the presence of anterior flanges of the lateral process, which are only present in 362 theropods (Rauhut, 2003a). Because of its rod-like haemal spine, DfMMh/FV/766 is a chevron 363 from the anterior part of the caudal axial series. Theropod chevrons are not well described in the 364 literature, making a precise taxonomic assessment of DfMMh/FV/776 difficult. However, a few 365 general comparisons can be made. The relatively robust, weakly posteriorly oriented haemal arch 366 is widespread among neotheropods, including non-tetanurans (e.g. Dilophosaurus wetherilli:

367 Welles, 1984; Ceratosaurus sp.: Madsen \& Welles, 2000) and tetanurans (e.g. Allosaurus

368 fragilis: Madsen, 1976). Most theropods show a subdivision of the articular facet into an anterior and a posterior subfacet, which are usually separated by a transverse ridge. DfMMh/FV/766 lacks such a subdivision, and instead has a single articular facet. Carrano, Benson \& Sampson (2012) found chevrons without a subdivided facet but low lateral mounds on each side as a putative synapomorphy of Megalosauroidea (e.g. present in Torvosaurus tanneris, Baryonyx walkeri, Afrovenator abakensis). However, undivided articulation facets have also been described for chevrons of ceratosaurs (Bonaparte, Benson \& Coria, 1990; Coria \& Salgardo, 1998; O'Connor, 2007), some of which show this feature only in the first chevron (e.g. Majungasaurus crenatissimus: O'Connor 2007). This indicates that the character has a wider distribution than recognized by Carrano, Benson \& Sampson (2012). The relatively small size of the anterior flanges of DfMMh/FV/776 matches the condition described for ceratosaurs better than for megalosauroids, in which the flanges are either absent altogether (e.g. Baryonyx walkeri: Charig \& Milner, 1998), or relatively pointed (e.g. Torvosaurus tanneri: Britt, 1991). Allosauroids usually have more prominent and anteriorly pointed anterior flanges (e.g. Madsen, 1976; Zanno \& Makovicky, 2013; Malafaia et al., 2016), making it unlikely that DfMMh/FV/776 represents an allosauroid. The straight haemal arch of DfMMh/FV/776 is also compatible with ceratosaurian affinities (e.g. Ceratosaurus sp.: Madsen \& Welles, 2000; Carnotaurus sastrai: Bonaparte, Novas \& Coria, 1990), but is also observed in some megalosaurs such as Torvosaurus tanneri (Britt, 1991). The anterior median keel observed ofr $\mathrm{DfMMh} / \mathrm{FV} / 776$ is peculiar, as it is a relatively prominent feature. We have not seen a comparative ridge in allosauroids (e.g. Madsen, 1976), and the keel also seems to be absent in megalosaurus such as Torvosaurus tanneri (Britt, 1991). Carnotaurus sastrai seems to have a weak anterior ridge (Bonaparte, Novas \& Coria, 1990), but this feature is much more pronounced in. Based on these limited comparisons, DfMMh/FV/776 is most compatible with

392 the chevron morphology observed in ceratosaurs, although megalosauroid affinities cannot be 393 ruled out entirely. 
394

395

396

397

398

399

400

401

402

403

404

405

406

407

408

409

410

411

412

413

414

415

416

417

418

419

420

421

422

423

424

425

426

427

428

429

430

431

432

433
Dinosauria Owen, 1842

Theropoda Marsh, 1881

Tetanurae Gauthier, 1986

cf. Megalosauroidea (Fitzinger, 1843) Walker, 1964

Material: DfMMh/FV/287, left fibula (Figure 4A-E).

Description: DfMMh/FV/287 is a partially preserved left fibula, in which the distal end is missing. The proximal part of the fibula is expanded anteroposteriorly to form the fibular head, and distally the element forms a slender shaft (Figure 4A-E). The expansion of the fibular head relative to the shaft is asymmetric, and proportionally stringer on the posterior side: The posterior margin of the fibular head forms a convexly rounded process, which is separated from more distal parts of the fibula by a gentle notch. The posterior margin of the fibular head is formed as a transversely thin edge. In contrast, the anterior side of the fibular head expands more gradually, and forms a relatively thick and rounded margin. The fibular head is inflected medially (i.e. toward the tibia) at its anterior side, giving the proximal articular surface a crescentic outline (Figure 4C). On the medial surface, the fibular head bears a shallow, concave fossa (Figure 4E). The fossa is limited to the anterior and central parts of the medial surface, and does not extend onto the thin posterior expansion of the fibular head. Anteriorly, the fossa is well defined by a vertically projecting anteromedial ridge. The fossa extends distally to the level of the tubercle for the M. iliofibularis, and is developed as a deep trough just proximally to the tubercle. It remains unclear, if the present depth of the fossa is natural in this part of the bone, of if slight crushing hypertrophied this structure.

The proximal part of the fibula tapers distally to the level of the notch, until it reaches the tubercle for the M. iliofibularis. This tubercle is developed as a bulbous swelling with a rugose surface texture, which makes the fibula appear expanded in this part (Figure 4E). The tubercle is located on the anteromedial side of the bone, but covers most of the medial surface of the fibula as well.

Distally to the tubercle for the M. iliofibularis, the fibular shaft extends as a slender and rod-like structure. The fibular shaft is kinked posteriorly in respect to the proximal third of the fibula, best seen in lateral or medial view, but is itself straight. The shaft retains its width and depth along the rest of its preserved length. The fibular shaft is slightly longer anteroposteriorly than it is transversely wide, and it is conspicuously concavo-concex, whereby the lateral surface of the cone is strongly convexely rounded. The medial surface of the shaft is furrowed by a longitudinal groove. The distal end of the fibula is broken off, so that it is unclear if and how the bone expands to articulate with the tarsus.

Remarks: The fibula DfMMh/FV/287 can be assigned to the Theropoda because of the presence of a marked M. iliofibularis tubercle, which is only found in theropods among dinosaurs (Rauhut, 2003a). Within Theropoda, DfMMh/FV/287 represents a member of the Averostra, because of the presence of the fossa on the medial surface of the fibular head, which is absent in earlier branching lineages such as coelophysids (Rauhut, 2003a). It is unlikely that 
$434 \mathrm{DfMMh} / \mathrm{FV} / 287$ belongs to a ceratosaur, because the fossa on the medial surface in these

435

436

437

438

439

440

441

442

443

444

445

446

447

448

449

450

451

452

453

454

455

456

457

458

459

460

461

462

463

464

465

466

467

468

469

470

471

472

473

theropods is usually very deep and anteriorly and posteriorly bound by well-defined ridges (e.g. Ceratosaurus sp.: UMNH VP 5278, Madsen \& Welles, 2000; Eoabelisaurus mefi: Pol \& Rauhut, 2012; Elaphrosaurus bambergi: Rauhut \& Carrano, 2016). Additionally, the medial surface of the shaft is not concave in ceratosaurs such as Ceratosaurus (UMNH VP 5278), whereas this is the case in basal tetanurans, including allosauroids (e.g. Allosaurus fragilis: UMNH VP 7949) or megalosauroids (e.g. Afrovenator abakensis: UC OBA 1). Among the Tetanurae, $\mathrm{DfMMh} / \mathrm{FV} / 287$ is most similar to megalosauroids, some of which share the unusually shallow medial fossae with DfMMh/FV/287 (e.g. Suchomimus tenerensis: MNN GDF501; Torvosaurus tanneri: BYU VP 9620; Britt, 1991; Benson, 2010). In allosauroids, such as Allosaurus fragilis (Madsen, 1976), Neovenator salerii (MIWG 6348; Brusatte et al., 2008), or Australovenator wintonensis (White et al., 2013), the medial fossae are usually deeper, and proximally well bound by a sharp margin, whereas the fossa on $\mathrm{DfMMh} / \mathrm{FV} / 287$ simply becomes shallower proximally.

Dinosauria Owen, 1842

Theropoda Marsh, 1881

cf. Tetanurae Gauthier, 1986

Material: DfMMh/FV/105, distal caudal vertebra (Figure 3F-K).

Description: DfMMh/FV/105 is identified as a distal caudal vertebra based on its general centrum dimensions and development of neural arch processes. The vertebra is incomplete, as the posterior intervertebral articulation is ventrally splintered obscuring most of the ventral surface, and the prezygapophyses are broken at their bases. However, the delicate postzygapophyses are preserved.

The centrum of DfMMh/FV/105 is anteroposteriorly elongate and measures $33 \mathrm{~mm}$ in length. The intercentral articulations are thus broader than high $(12 \mathrm{~mm}$ wide and $9 \mathrm{~mm}$ high for the anterior facet; Figure $3 \mathrm{H}$ ), and reniform in shape. The facets are slightly concave, and the vertebra is accordingly amphyplatian/amphicoelous. The exposed anterior intercentral articulation is dorsoventrally and transversely expanded in relation to the mid-centrum, so that the centrum is centrally gently constricted. The lateral surface of the centrum bears a longitudinal ridge on either side, which is sometimes observed in posterior caudal vertebrae past the transition point, i.e. the vertebral position after which the transverse processes are fully reduced in theropod dinosaurs. A cross-section through the central part of the centrum would be hexagonal because of the lateral ridge on either side.

The neural arch is low and elongate (Figure 3F-K), but does not cover the centrum from end to end. Instead, the neural arch is removed from the dorsal margin of the anterior and posterior intercentral articulations, exposing a broad floor of bone anterior to the entry and posterior to the exit of the neural canal. The prezygapophyses are broken off, but their remaining pedicles suggest that they were larger than the postzygapophyses, and diverged slightly from the midline, as commonly found in theropods. The neural arch between the pre- and postzygapophyses is a continuously low table of bone, which is transversely narrower than the centrum.

Peer) reviewing PDF | (2019:11:43051:1:1:NEW 18 Dec 2019) 
474 The postzygapophyses are delicate processes (Figure 3J-K), which are only weakly diverged 475 from the midline. They overhang the posterior end of the centrum by a few millimetres. The

476

477

478

479

480

481

482

483

484

485

486

487

488

489

490

491

492

493

494

495

496

497

498

499

500

501

502

503

504

505

506

507

508

509

510

511

512

513 postzygapophyses are slightly twisted, so that their articulation facets point progressively more ventrally as they are approaching their distal tip; while the articulation facets are basically laterally oriented at the base of the postzygapophyses, the facets have a strongly lateroventral inclination at their tips. This suggests, that the (unpreserved) prezygapophyses reached far onto preceding vertebrae, as is the case for many theropods.

The dorsal surface of the neural arch is completely flat in the anterior and central part of the vertebra, but a small, ridge-like protrusion can be found in between of the postzygapophyses. This protrusion likely represents a low neural spine, which gets progressively reduced along the caudal vertebral series of theropods.

Remarks: DfMMh/FV/105 is identified to be a theropod, and most likely a basal tetanuran, primarily on the basis of relatively elongate prezygapophyses (indicated by the position and shape of the postzygapophyses). In non-theropod dinosaurs, as well as more basal theropods such as Dilophosaurus wetherilli or Ceratosaurus sp., the prezygapophyses are generally much shorter in distal caudal vertebrae and do not extend far beyond the preceeding vertebra (Rauhut, 2003a).

Dinosauria Owen, 1842

Theropoda Marsh, 1881

Material: DfMMh/FV2/19, a small pedal phalanx III-1 (Figure 2K-P).

Description: DfMMh/FV2/19 is nearly completely preserved phalanx, with minor damage near the extensor groove, the right dorsal margin of the proximal facet, and around the ventral surface near the proximal end of the bone. The small phalanx is identified as a first pedal phalanx of the third digit of a theropod dinosaur, because of its broad and ventrally relatively flat proximal end, the non-saddle shaped proximal articulation surface, relatively long phalangeal shaft, and ginglymoid distal joint. It is unlikely that the phalanx represents a manual element, as the combination of a broad proximal end and a concave proximal joint surface are usually not found in manual phalanges (the first phalanx of the first manual digit usually has a saddle-shaped joint to mirror the condition of the first metacarpal, and the first phalanx of the manual second digit is usually relatively slender and less broad; e.g. Allosaurus fragilis: Gilmore, 1920, Madsen, 1976). $\mathrm{DfMMh} / \mathrm{FV} 2 / 19$ is relatively elongate and slender: It measures $10 \mathrm{~mm}$ proximodistally and a true phalangeal shaft separates the proximal and distal joints. This morphology is consistent with a first or second phalangeal position of the second or third digit, as other phalanges are usually stout and lack long phalangeal shafts (e.g. Allosaurus fragilis: Madsen, 1976). The phalangeal shaft of DfMMh/FV2/19 is transversely constricted in respect to the proximal and distal articulations, and is near circular in cross-section.

The proximal surface of DfMMh/FV2/19 is dorsally rounded and ventrally flat, therefore being ' $\mathrm{D}$ '-shaped (Figure 2M). It is $5 \mathrm{~mm}$ wide transversely, and $3 \mathrm{~mm}$ high dorsoventrally. The proximal articular surface is a single deep concavity. This is typical of first phalanges, which articulate with the broad trochlea of the metatarsalia, while more distally positioned phalanges 
514 usually have a saddle-shaped proximal joint that receives the condyles of preceding ginglymoid 515 articulations typical for phalanges. The right dorsal margin of the proximal joint is unfortunately 516 partly broken, but it seems that an extensor tubercle was very small if present at all. This again 517 fits the morphological expectations for a first pedal phalanx.

518 The distal joint is ginglymoid, with a lateral and medial condyle (although it is not sure, which 519 side is medial and which is lateral as it is currently not known whether the phalanx represents a left or right element) (Figure 2P). Both condyles are subequal in size, and are separated from one another by a vertical intercondylar sulcus, that curves around the distal end of the bone. The condyles are slightly rotated anteriorly, so that they are ventrally stronger expanded than dorsally, and inclined outwards, so that the intercondylar sulcus gets broader anteroventrally. The sulcus opens into a shallow flexor groove posteriorly and ventrally. On the dorsal surface, just proximally to the condyles, there is a relatively deep extensor groove present, but its depth might be exaggerated by minor breakage around this part. Collateral ligament pits are hard to discern on the phalanx; on one side, it appears that no pit is present at all, and on the other side there is only a minor depression near the dorsal surface of the condyle (Figure 2O). Remarks: The phalanx DfMMh/FV2/19 is herein identified as belonging to an indeterminate theropod dinosaur. The relatively strongly ginglymoid distal articulation and ' $\mathrm{D}$ '-shaped proximal articulation, combined with a relatively narrow and long phalangeal shaft are consistent with this interpretation. Phalanges of Jurassic turtles such as thalassochelydians have flatter shafts, often more broadly expanded proximal and distal ends, and the articular surfaces are less pronounced than in DfMMh/FV2/19 (e.g. Eurysternum wagleri, BSPG 1960 VIII 43). Pseudosuchian phalanges, for example from the Late Jurassic crocodyliform Alligatorellus sp., are usually more elongate and gracile than observed for DfMMh/FV2/19 (e.g. Tennant \& Mannion, 2014).

Dinosauria Owen, 1842

Theropoda Marsh, 1881

Material: DfMMh/FV3/19, proximal part of a small right fibula (Figure 4F-J).

$\mathrm{DfMMh} / \mathrm{FV} 3 / 19$ is a small fragment of a long bone, as it preserves parts of a shaft and one expanded terminal end. This specimen is herein identified as the proximal end of a right fibula of a theropod. The expanded proximal end of the specimen is relatively thick on one side, and thinedged on the other side. The thicker side is interpreted to be the transversely expanded anterior side of the fibula (Figure 4F), and the thin-edged side is interpreted to be the posterior margin of the fibula (Figure 4I). However, fibulae are usually posteriorly stronger expanded than anteriorly, which is not the case in DfMMh/FV3/19. The presence of a large but shallow depression on what is interpreted as the medial side is consistent with the gross anatomy of a fibula.

The anterior and posterior sides of $\mathrm{DfMMh} / \mathrm{FV} 3 / 19$ are slightly arched inwards towards the proximal end of the bone, so that the fibular head is gently crescentic. The surface of the articular facet is domed in its central part, and dips ventrally on the anterior side (Figure 4H). The anterior margin of the articular facet forms a small lip that protrudes slightly anteriorly. The lateral 
554 surface of the fibular head is convexly rounded but becomes relatively flat towards the posterior

555

556

557

558

559

560

561

562

563

564

565

566

567

568

569

570

571

572

573

574

575

576

577

578

579

580

581

582

583

584

585

586

587

588

589

590

591

592

593

side of the specimen. Just beneath the articular surface, the rounded anterior margin of $\mathrm{DfMMh} / \mathrm{FV} 3 / 19$ is raised to a short tubercle or protuberance with slightly rugose surface texture that indicates the origin or insertion of some soft tissue structure. Posteriorly, the sharp-edged margin of the bone extends ventrally toward the shaft, and levels off reaching before the shaft. On the medial side, the fibular head is characterised by a low, vaguely triangular concavity (Figure 2J). The concavity is not well defined to either side, and spans more or less the entire space of the fibular head. The concavity narrows distally where it approaches the shaft, and finally vanishes just prior to a medial thickening of the fibular shaft.

The fibular shaft is broken shortly distal to the fibular head. The cross section of the break shows that the fibular shaft was circular in its proximal part.

Remarks: The described morphology of DfMMh/FV3/19 is consistent with its identification of an indeterminate theropodan fibula.

\section{Discussion}

Most German finds of Late Jurassic theropods are confined to the lagerstätten deposits of the Solnhofen area in Southern Germany, and include coelurosaurian theropods such as Juravenator starki (Göhlich \& Chiappe, 2006), Archaeopteryx lithographica and closely related avian theropods (e.g. Foth, Tischlinger \& Rauhut, 2014; Foth \& Rauhut, 2017; Rauhut et al., 2019), as well as the megalosauroid Sciurumimus albersdoerferi (Rauhut et al., 2012). Relatively complete theropod material from Northern Germany has been found in about $10 \mathrm{Myr}$ older deposits from the Callovian, and belongs to the megalosauroid Wiehenvenator albati (Rauhut, Hübner \& Lanser, 2016). On the basis of isolated teeth, Gerke \& Wings (2016) found evidence for the presence of tyrannosauroids, allosauroids, megalosauroids, and ceratosaurs in the Langenberg Quarry. However, the findings of van der Lubbe, Richter \& Knötschke (2009), who reported on the presence of velociraptorine teeth from the Langenberg Quarry, could not be confirmed (Gerke \& Wings, 2016). The fossils described in this contribution, interpreted as belonging to allosauroid, megalosauroid, ceratosaurian, and indeterminate theropods, represent the first body fossil evidence of theropods for the Langenberg Quarry. All of our material belongs to relatively small individuals. The ontogenetic stages of the material are currently unknown, but the presence of large theropod tracks in the Langenberg Quarry (Lallensack et al., 2015) demonstrates that large-bodied individuals were at least temporarily present in the habitat of today's Langenberg Quarry. The fossil tooth, body fossil, and track record from Langenberg indicates a relatively high diversity of basal averostrans (i.e. ceratosaurs and basal tetanurans), which are rare elements of the Solnhofen archipelago limestone deposits. Despite the regional differences in faunal composition between different German basins, and although the Late Jurassic theropod fauna of Germany remains patchy, it is clear that all major groups of theropods that lived during the Late Jurassic were also present in Germany.

The Late Jurassic theropod dinosaur record in other parts of Europe is mostly similarly patchy, but also confirms the presence of several theropod lineages in Europe during the Late Jurassic.

Peer) reviewing PDF | (2019:11:43051:1:1:NEW 18 Dec 2019) 
594 From the United Kingdom, diagnostic material is known from several formations and several 595 stages of the Late Jurassic. For instance, the tyrannosauroid Juratyrant langhami is known from 596 the Tithonian Kimmeridge Clay (Benson, 2008; Brusatte \& Benson, 2013), whereas the 597 allosauroid Metriacanthosaurus parkeri and the megalosauroid Eustreptospondylus oxoniensis 598 are known from the older, Callovian-Oxfordian, Oxford Clay (Sadleir, Barrett \& Powell, 2008; 599 Carrano, Benson \& Sampson, 2012).

600 Some of the best and most complete theropod material in Europe comes from Late

601 Kimmeridgian-Tithonian formations in the Lusitanian Basin of Portugal, including the Lourinhã 602 and Alcobaça Formations. The Portuguese theropod fauna includes the allosauroid Allosaurus 603 europaeus (Mateus, Walen \& Antunes, 2006), the ceratosaur Ceratosaurus sp. (Mateus \& 604 Antunes, 2000), the megalosauroid Torvosaurus gurneyi (Hendrickx \& Mateus, 2014; Malafaia 605 et al., 2017), the allosauroid Lourinhanosaurus antuneso (Mateus, 1998; Benson, 2010), the 606 tyrannosauroid Aviatyrannis jurassica (Rauhut, 2003b). The faunal composition of the 607 Portuguese record has been interpreted to be very similar to the much better documented 608 equivalent North American fauna from the Morrison Formation (Mateus, 2006; Mateus, Walen 609 \& Antunes, 2006; Pol \& Rauhut, 2012; Hendrickx \& Mateus, 2014).

610

\section{Conclusions}

612 We present new occurrences of theropod dinosaurs from the Late Jurassic Langenberg Quarry of 613 northern Germany. The incomplete material can be assigned to certosaurian, megalosauroid, and 614 allosauroid theropods. These identifications agree with previous reports of the presence of these 615 theropod groups in the Late Jurassic of Northern Germany based on teeth. Although the

616 Langenberg theropod fauna is not as rich as some other European localities, such as the Lourinhã

617 Formation of Portugal, our findings confirm a varied dinosaur fauna in central Europe and add to 618 our incomplete understanding of theropod diversity and evolution during the Late Jurassic of 619 Europe.

620

621 Acknowledgements

622 We would like to thank Nils Knötschke and his team from the Dinosaurier-Park Münchehagen

623 for collecting the material in the field and the exquisite preparation. Special thanks to the late

624 Fabian von Pupka as well as Janna von Pupka, her team and family at the Rohstoffbetriebe Oker $625 \mathrm{GmbH} \& \mathrm{Co}$. KG for the permission to access the Langenberg Quarry and for providing logistic 626 support during fieldwork.

627 We would like to thank Jonah Choiniere (University of the Witwatersrand), Oliver Rauhut 628 (Bayerische Staatssammlung für Paläontologie und Geologie) and Mark Loewen (University of 629 Utah) for providing images of comparative material.

630 Finally yet importantly, we would like to thank all excavation volunteers and preparators for 631 their work on the Langenberg material. 


\section{References}

633 Anquetin J, Püntener C, Joyce WG. 2017. A review of the fossil record of Turtles of the Clade

634 Thalassochelydia. Bulletin of the Peabody Museum of Natural History 58(2):317-369 DOI

$63510.3374 / 014.058 .0205$.

636 Anquetin J, Joyce WG. 2014. A reassessment of the Late Jurassic turtle Eurysternon wagleri

637 (Eucryptodira, Eurysternidae). Journal of Vertebrate Paleontology 34(6):13171328 DOI

638 10.1080/02724634.2014.880449

639 Barrett PM, McGowan AJ, Page V. 2009. Dinosaur diversity and the rock record. Proceedings

640 of the Royal Society B 276(1667): https://doi.org/10.1098/rspb.2009.0352

641 Benson RBJ. 2008. New information on Stokesosaurus, a tyrannosauroid (Dinosauria:

642 Theropoda) from North America and the United Kingdom. Journal of Vertebrate Paleontology

643 28(3):732-750.

644 Benson RBJ. 2010. A description of Megalosaurus bucklandii (Dinosauria: Theropoda) from

645 the Bathonian of the UK and the relationships of Middle Jurassic theropods. Zoological Journal

646 of the Linnean Society 158: 882-935. https://doi.org/10.1111/j.1096-3642.2009.00569.x

647 Benson RBJ, Carrano MT, Brusatte SL. 2010. A new clade of archaic large-bodied predatory

648 dinosaurs (Theropoda: Allosauroidea) that survived to the latest Mesozoic. Naturwissenschaften

649 97:71-78. DOI 10.1007/s00114-0614-x

650 Benson RBJ, Campione NE, Carrano MT, Mannion PD, Sullivan C, Upchurch P, Evans

651 DC. 2014. Rates of dinosaur body mass evolution indicate 170 million years of sustained

652 ecological innovation on the avian stem lineage. PloS Biology 12(5): e1001853. DOI

653 10.1371/journal.pbio.1001853

654 Bonaparte JF, Novas FE, Coria RA. 1990. Carnotaurus sastrei Bonaparte, the horned, lightly

655 built carnosaur from the middle Cretaceous of Patagonia. Contributions in Science, Serial

656 Publications of the Natural History Museum of Los Angeles County 416:2-41.

657 Britt BB. 1991. Theropods of Dry Mesa Quarry (Morrison Formation, Late Jurassic), Colorado,

658 with emphasis on the osteology of Torvosaurus tanneri. BYU Geology Studies 37:1-72.

659 Brusatte SL, Benson RBJ. 2013. The systematics of Late Jurassic tyrannosauroid theropods

660 from Europe and North America. Acta Palaeontologica Polonica 58(1):47-54.

661 Carballido JL, Sander PM. 2013. Postcranial axial skeleton of Europasaurus holgeri

662 (Dinosauria, Sauropoda) from the Upper Jurassic of Germany: implications for sauropod

663 ontogeny and phylogenetic relationships of basal Macronaria. Journal of Systematic

664 Palaeontology 12:1-53. DOI 10.1080/14772019.2013.764935

665 Carrano MT. 2007. The appendicular skeleton of Majungasaurus crenatissimus (Theropoda:

666 Abelisauridae) from the Late Cretaceous of Madagascar. Society of Vertebrate Paleontology

667 Memoir 8:163-179.

668 Carrano MT, Sampson SC, Forster CA. 2002. The osteology of Masiakasaurus knopfleri, a

669 small abelisauroid (Dinosauria: Theropoda) from the Late Cretaceous of Madagascar. Journal of

670 Vertebrate Paleontology 22(3):510-534. DOI 10.1671/0272-

671 4634(2002)002[0510:TOOMKA]2.0.CO;2 
672 Carrano MT, Benson RBJ, Sampson SD. 2012. The phylogeny of Tetanurae (Dinosauria:

673 Theropoda). Journal of Systematic Palaeontology 10:211-300.

674 DOI 10.1080/14772019.2011.630927.

675 Charig AJ, Milner AC. 1997. Baryonyx walkeri, a fish-eating dinosaur from the Wealden of

676 Surrey. Bulletin of the Natural History Museum Geology 53:11-70.

677 Close RA, Evers SW, Alroy J, Butler R. 2018. How should we estimate diversity in the fossil

678 record? Testing richness estimators using sampling-standardised discovery curves. Methods in

679 Ecology and Evolution 9(6):1286-1400.

680 Coria RA, Salgardo L. 1998. A basal Abelisauria Novas, 1992 (Theropoda-Ceratosauria) from

681 the Cretaceous of Patagonia, Argentina. Gaia 15:89-102.

682 Currie PJ, Zhao X-J. 1993. A new carnosaur (Dinosauria, Theropoda) from the Jurassic of

683 Xinjiang, People's Republic of China. Canadian Journal of Earth Sciences 30:2037-2081.

684 Evers SW, Benson RBJ. 2019. A new phylogenetic hypothesis of turtles with implications for

685 the number of evolutionary transitions to marine lifestyles supports an Early Cretaceous origin

686 and rapid diversification of Chelonioidea. Palaeontology 62(1):93-134.

687 DOI 10.1111/pala.12384.

688 Fastnacht M. 2005. The first dsungaripterid pterosaur from the Kimmeridgian of Germany and

689 the biomechanics of pterosaur long bones. Acta Palaeontologica Polonica 50:273-288.

690 Fischer R. 1991. Die Oberjura-Schichtenfolge des Langenbergs bei Oker. Arbeitskreis

691 Paläontologie Hannover 19:21-36.

692 Fitzinger L. 1843. Sytema reptilium. Fasciculus primus: Amblyglossae. Vienna: Apud

693 Braumüller and Seidel Bibliopolas.

694 Foth C, Rauhut OWM. 2017. Re-evaluation of the Haarlem Archaeopteryx and the radiation of 695 maniraptoran theropod dinosaurs. BMC Evolutionary Biology 17(263). DOI 10.1186/s12862-

696 017-1076-y

697 Foth C, Tischlinger H, Rauhut OWM. 2014. New specimen of Archaeopteryx provides

698 insights into the evolution of pennaceous feathers. Nature 511(7507):79-82.

699 Gauthier JA. 1986. Saurischian monophyly and the origin of birds. Memoirs of the California

700 Academy of Science 8:1-55.

701 Gerke O, Wings O. 2016. Multivariate and cladistic analyses of isolated teeth reveal sympatry

702 of theropod dinosaurs in the Late Jurassic of Northern Germany PLoS ONE 11:e0158334. DOI

703 10.1371/journal.pone. 0158334

704 Gilmore GW. 1920. Osteology of the carnivorous Dinosauria in the United States National

705 Museum, with special reference to the genera Antrodemus (Allosaurus) and Ceratosaurus.

706 Bulletin of the United States National Museum 110:1-159.

707 Hendrickx C, Mateus O. 2014. Torvosaurus gurneyi n. sp., the largest terrestrial predator from

708 Europe, and a proposed terminology of the maxilla anatomy in nonavian theropods. PLoS One

709 9(3): e88905. 
|710 Hocknull SA, White MA, Tischler TR, Cook AG, Calleja ND, Sloan T, Elliott DA. 2009.

711 New mid-Cretaceous (latest Albian) dinosaurs from Winton, Queensland, Australia. PloS ONE

712 4(7):e6190. DOI 10.1371/journal.pone.0006190

713 Jansen M, Klein N. 2014. A juvenile turtle (Testudines, Eucryptodira) from the Upper Jurassic

714 of Langenberg Quarry, Oker, Northern Germany. Palaeontology 57:743-756.

71510.1111 pala.12085

716 Joyce WG. 2000. The first complete skeleton of Solnhofia parsoni (Cryptodira, Eurysternidae)

717 from the Upper Jurassic of Germany and its taxonomic implications. Journal of Paleontology

718 74(4):684-700.

719 Karl HV, Gröning E, Brauckmann C, Schwarz D, Knötschke N. 2006. The Late Jurassic

720 crocodiles of the Langenberg near Oker, Lower Saxony (Germany), and description of related

721 materials (with remarks on the history of quarrying the "Langenberg Limestone" and

722 "Obernkirchen Sandstone"). Clausthaler Geowissenschaften 5:59-77.

723 Karl H-V, Gröning E, Brauckmann C, Knötschke N. 2008. First remains of the head of

724 Steneosaurus (Crocodylomorpha: Teleosauridae) from the Late Jurassic of Oker (Lower Saxony,

725 Germany). Studia Geologica Salmanticensia 44(2):187-201.

726 Lallensack JN, Sander PM, Knötschke N, Wings O. 2015. Dinosaur tracks from the

727 Langenberg Quarry (Late Jurassic, Germany) reconstructed with historical photogrammetry:

728 Evidence for large theropods soon after insular dwarfism. Palaeontologia Electronica

729 18.2.31A:1-34.

730 Lloyd GT, Davies KE, Pisani D, Tarver JE, Ruta M, Sakamoto M, Hone DWE, Jennings R,

731 Benton MJ. 2008. Dinosaurs and the Cretaceous Terrestrial Revolution. Proceedings of the

732 Royal Society B 275 (1650): https://doi.org/10.1098/rspb.2008.0715

733 Lotze F. 1968. Zum Jura des Langenberges zwischen Oker und Bad Harzburg (nördl. Harzrand).

734 Neues Jahrbuch für Geologie und Paläontologie, Monatshefte 1968:730-732.

735 van der Lubbe T, Richter U, Knötschke N. 2009. Velociraptorine dromoesaurid teeth from the

736 Kimmeridgian (Late Jurassic) of Germany. Acta Palaeontologica Polonica 54(3):401-408. DOI

737 10.4202/app.2008.0007

738 Madsen JHJ. 1976. Allosaurus fragilis: a revised osteology. Utah Geological and

739 Mineralogical Survey Bulletin 109:3-163.

740 Madsen JHJ, Welles SP. 2000. Ceratosaurus (Dinosauria, Theropoda), a revised osteology.

741 Utah Geology Survey Miscellaneous Publication 00-2:1-80.

742 Mannion PD, Upchurch P, Carrano MT, Barrett PM. 2011. Testing the effect of the rock

743 record on diversity: a multidisciplinary approach to elucidating the generic richness of

744 sauropodomorph dinosaurs through time. Biological Reviews 86: 157-181

745 Malafaia E, Mocho P, Escaso F, Ortega F. 2016. A juvenile allosauroid theropod (Dinosauria,

746 Saurischia) from the Upper Jurassic of Protugal. Historical Biology 29(5):654-676.

747 Malafaia E, Mocho P, Escaso F, Ortega F. 2017. New data on the anatomy of Torvosaurus and

748 other remains of megalosauroid (Dinosauria, Theropoda) from the Upper Jurassic of Portugal.

749 Iberian Journal of Geology 43(1):33-59. 
750 Marpmann JS, Carballido JL, Sander PM, Knötschke N. 2014. Cranial anatomy of the Late

751 Jurassic dwarf sauropod Europasaurus holgeri (Dinosauria, Camarasauromorpha): ontogenetic

752 changes and size dimorphism. Journal of Systematic Palaeontology:1-43.

753 10.1080/14772019.2013.875074

754 Marsh OC. 1878. Notice of new dinosaurian reptiles. The American Journal of Science and

755 Arts, Series 3, 15:241-244.

756 Marsh OC. 1881. Classification of the Dinosauria. American Journal of Science Series 3:241-

757244.

758 Marsh OC. 1884. Principal characters of American Jurassic dinosaurs. Part VIII. The order

759 Theropoda. The American Journal of Sience and Arts, Series 3 27:329-340

760 Martin T, Schultz JA, Schwermann AH, Wings O. 2016. First Jurassic mammals of Germany:

761 Multituberculate teeth from the Late Jurassic Langenberg Quarry near Goslar (Lower Saxony).

762 Acta Palaeontologica Polonica 67:171-179.

763 Martin T, Averianov AO, Schultz JA, Schwermann AH, Wings O. 2019. Late Jurassic

764 multituberculate mammals from Langenberg Quarry (Lower Saxony, Germany) and

765 palaeobiogeography of European Jurassic multituberculates. Historical Biology:1-14. DOI

$76610.1080 / 08912963.2019 .1650274$

767 Martin T, Averianov AO, Jäger, KRK, Schwermann AH, and Wings O. In press. A large

768 morganucodontan mammaliaform from the Late Jurassic of Germany. Fossil Imprint.

769 Mateus O. 1998. Lourinhanosaurus antunesi, a new Upper Jurassic allosauroid (Dinosauria:

770 Theropoda) from Lourinhã, Portugal. Memórias da Academia de Ciências de Lisboa. 37:111-

771124.

772 Mateus O. 2006. Late Jurassic dinosaurs from the Morrison Formation (USA), the Lourinhã and

773 Alcobaça Formations (Portugal), and the Tendaguru beds (Tanzania): a comparison. New Mexico

774 Museum of Natural History and Science Bulletin 36:223-231.

775 Mateus O, Antunes MT. 2000. Ceratosaurus sp. (Dinosauria: Theropoda) in the Late Jurassic

776 of Portugal. [Abstract] 31st International Geological Congress, Rio de Janeiro, Brazil, 2000.

777 Mateus O, Walen A, Telles Antunes M. 2006. The large theropod fauna of the Lourinhã

778 Formation (Portugal) and its similarity to the Morrison Formation, with a description of a new

779 species of Allosaurus. New Mexico Museum of Natural History and Science Bulletin 36:123-

780129.

781 McAllister Rees P, Noto CR, Parrish JM, Parish JT. 2004. Late Jurassic climates, vegetation, 782 and dinosaur distributions. The Journal of Geology 112(6):643-653.

783 Mudroch A. 2001. Fischzähne aus dem Oberjura Nordwesteuropas - Systematik, Biogeochemie 784 und Palökologie. PhD. Thesis Universität Hannover.

785 Mudroch A, Thies D. 1996. Knochenfischzähne (Osteichthyes, Actinopterygii) aus dem

786 Oberjura (Kimmeridgium) des Langenbergs bei Oker (Norddeutschland). Geologica et

787 Palaeontologica 30:239-265. 
788 O'Connor PM. 2007. The postcranial axial skeleton of Majungasaurus crenatissimus

789 (Theropoda: Abelisauridae) from the Late Cretaceous of Madagascar. Journal of Vertebrate

790 Paleontology 27:127-163 DOI 10.1671/0272-4634(2007)27[127:TPASOM]2.0.CO;2.

791 Owen R. 1842. Report on British fossil reptiles. Part II. Report of the British Association for the

792 Advancement of Science 11:60-204.

793 Pape H. 1970. Die Malmschichtfolge vom Langenberg bei Oker (nördl. Harzvorland).

794 Mitteilungen aus dem Geologischen Institut der Technischen Universität Hannover 9:41-134.

795 Paul GS. 1988. Predatory Dinosaurs of the World. Simon \& Schuster, New York, 464 pp.

796 Pol D, Rauhut OWM. 2012. A Middle Jurassic abelisaurid from Patagonia and the early

797 diversification of theropod dinosaurs. Proceedings of the Royal Society B 279(1741):3170-3175.

798 DOI 10.1098/rspb.2012.0660

799 Rauhut OWM. 2003a. The interrelationships and evolution of basal theropod dinosaurs. Special

800 Papers in Palaeontology 69:1-216.

801 Rauhut OWM. 2003b. A tyrannosauroid dinosaur from the Late Jurassic of Portugal.

802 Palaeontology 46(5):903-910.

803 Rauhut OWM, Carrano MT. 2016. The theropod dinosaurs Elaphrosaurus bambergi

804 Janensch, 1920, from the Late Jurassic of Tendaguru, Tanzania. Zoological Journal of the

805 Linnean Society 178(3):546-610. DOI 10.1111/zoj.12425

806 Rauhut OWM, Foth C, Tischlinger H, Norrell MA. 2012. Exceptionally preserved juvenile

807 megalosauroid theropod dinosaur with filamentous integument from the Late Jurassic of

808 Germany. Proceedings of the National Academy of Sciences 279(1741):3170-3175. DOI

809 10.1073/pnas.1203238109

810 Rauhut OWM, Hübner TR, Lanser K-P. 2016. A new megalosaurid theropod dinosaur from

811 the late Middle Jurassic (Callovian) of north-western Germany: implications for theropod

812 evolution and turnover in the Jurassic. Paleontologia Electronica 19(2): 29A. DOI 10.26879/654

813 Rauhut OWM, Tischlinger H, Foth C. 2019. A non-archaeopterygid avialan theropod from the

814 Late Jurassic of Southern Germany. eLife 8:e43789. DOI 10.7554/eLife.43789.001

815 Richter A, Knötschke N, Kosma R, Sobral G, Wings O. 2013. The first Mesozoic lizard from

816 northern Germany (Paramacellodidae, Late Jurassic, Langenberg Quarry) and its taphonomy.

817 Journal of Vertebrate Paleontology, Program and Abstracts, 2013:198.

818 Sadleir RW, Barrett PM, Powell HP. 2008. The anatomy and systematics of

819 Eustreptospondylus oxoniensis, a theropod dinosaur from the Middle Jurassic of Oxfordshire,

820 England. Monograph of the Palaeontological Society 627:1-82.

821 Sander PM, Mateus O, Laven T, Knötschke N. 2006. Bone histology indicates insular

822 dwarfism in a new Late Jurassic sauropod dinosaur. Nature 441:739-741. 10.1038/nature04633

823 Schwarz D, Raddatz M, Wings O. 2017. Knoetschkesuchus langenbergensis gen. nov. sp. nov.,

824 a new atoposaurid crocodyliform from the Upper Jurassic Langenberg Quarry (Lower Saxony,

825 northwestern Germany), and its relationships to Theriosuchus. PLoS ONE 12:e160617.

826 10.1371/journal.pone.0160617 
827 Schweigert G. 1999. Neue biostratigraphische Grundlagen zur Datierung des nordwestdeutschen 828 höheren Malm. Osnabrücker Naturwissenschaftliche Mitteilungen 25:25-40.

829 Tennant JP, Mannion PD. 2014. Revision of the Late Jurassic crocodyliform Alligatorellus,

830 and evidence for allopatric speciation driving high diversity in western European atoposaurids.

831 PeerJ 2:e599. DOI 10.7717/peerj.599

832 Tennant JP, Chiarenza AA, Baron M. 2018. How has our knowledge of dinosaur diversity

833 through geologic time changed through research history? PeerJ 6:e4417

834 https://doi.org/10.7717/peerj.4417

835 Thies D. 1995. Placoid scales (Chondrichthyes: Elasmobranchii) from the Late Jurassic

836 (Kimmeridgian) of northern Germany. Journal of Vertebrate Paleontology 15:463-481.

$837 \quad 10.1080 / 02724634.1995 .10011242$

838 Thies D, Windorf R, Mudroch A. 1997. First record of Atoposauridae (Crocodylia:

839 Metamesosuchia) in the Upper Jurassic (Kimmeridgian) of Northwest Germany. Neues Jahrbuch

840 für Geologie und Paläontologie 205:393-411.

841 Walker AD. 1964. Triassic reptiles from the Elgin area: Ornithosuchus and the origin of

842 carnosaurs. Philosophical Transactions of the Royal Society of London. Series B, Biological

843 Sciences 248(744):53-134.

844 Welles SP. 1984. Dilophosaurus wetherilli (Dinosauria, Theropoda) osteology and comparisons.

845 Palaeontographica Abteilung A 185:85-180.

846 White MA, Cook AG, Hocknull SA, Sloan T, Sinapius GHK, Elliott DA. 2012. New forearm

847 elements discovered of holotype specimen Australovenator wintonensis from Winton,

848 Queensland, Australia. PLoS ONE 7(6):e39364 DOI: 10.1371/journal.pone.0039364

849 White MA, Benson RBJ, Tischler TR, Hocknull SA, Cook AG, Barnes DG, Poropat SF, 850 Wooldridge SJ, Sloan T, Sinapius GHK, Elliott DA. 2013. New Australovenator hind limb

851 elements pertaining to the holotype reveal the most complete neovenatorid leg. PLoS ONE

852 8(7):e68649. DOI 10.1371/journal.pone.0068649

853 Wings O. 2015. The Langenberg Quarry near Goslar: Unique window into a terrestrial Late

854 Jurassic ecosystem in Northern Germany. In: Zhang Y, Wu SZ, Sun G, eds. [Abstracts] $12^{\text {th }}$

855 Symposium of Mesozoic Terrestrial Ecosystems, August 16th-20th 2015, Shenyang, China, pp.

$85699-100$.

857 Wings O, Sander PM. 2012. The Late Jurassic vertebrate assemblage of the Langenberg

858 Quarry, Oker, Northern Germany.- iFundamental!, 20: 281-284.

859 Zanno LE, Makovicky PJ. 2013. Neovenatorid theropods are apex predators in the Late

860 Cretaceous of North America. Nature communications 4(2827):1-9 DOI 10.1038/ncomms 3827

861 Ziegler PA. 1990. Geological Atlas of Western and Central Europe: Shell Internationale

862 Petroleum Maatschappij, The Hague.

863 Zuo F, Heimhofer U, Huck S, Luppold FW, Wings O, Erbacher J. 2017. Sedimentology and

864 depositional sequences of a Kimmeridgian carbonate ramp system, Lower Saxony Basin,

865 Northern Germany. Facies 64:1 (published online). 10.1007/s10347-017-0513-0 
Figure 1

Geographic location of the Langenberg Quarry in the Harz Mountains of Germany.

(A) Map of Germany with the Harz Mountains highlighted in grey and Langenberg Quarry (LQ) indicated by star. (B) Close-up of the Harz Mountain area with Langerberg Quarry and nearby towns indicated.

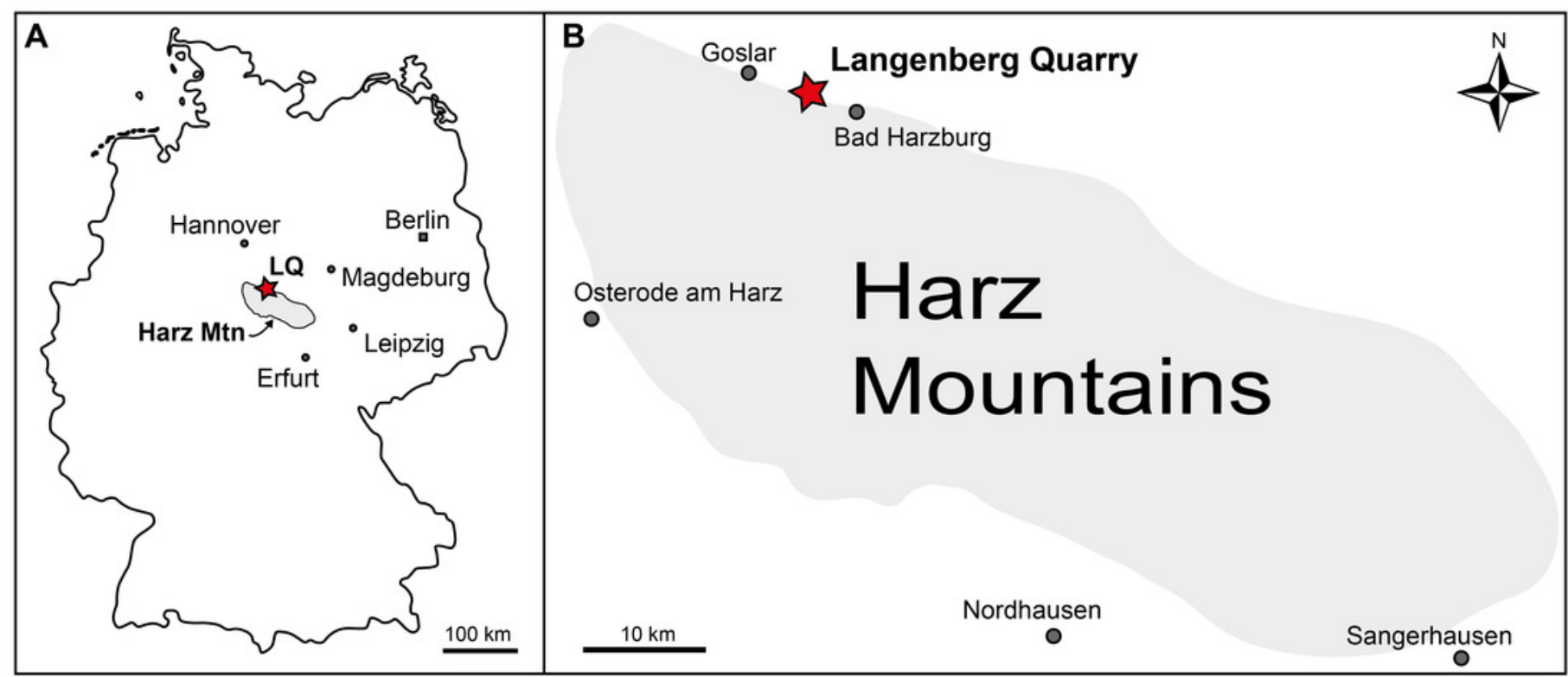




\section{Figure 2}

Isolated theropodan phalangeal elements from the Langenberg Quarry.

DfMMh/FV1/19, pedal ungual, in (A) dorsal view, (B) ventral view, (C) left lateral view, (D) right lateral view. DfMMh/FV/343, pedal phalanx, in (E) dorsal view, $(F)$ ventral view, $(G)$ distal view, (H) left lateral view, (I) right lateral view, (J) distal view. DfMMh/FV2/19, pedal phalanx, in (K) dorsal view, (L) ventral view, (M) distal view, (N) left lateral view, (O) right lateral view, (P) distal view. Abbreviations: cg, collateral groove; ext, extensor tubercle; fxf, flexor fossa; fxt, flexor tubercle; Ip, ligament pit. All scale bars equal $5 \mathrm{~mm}$. 
A

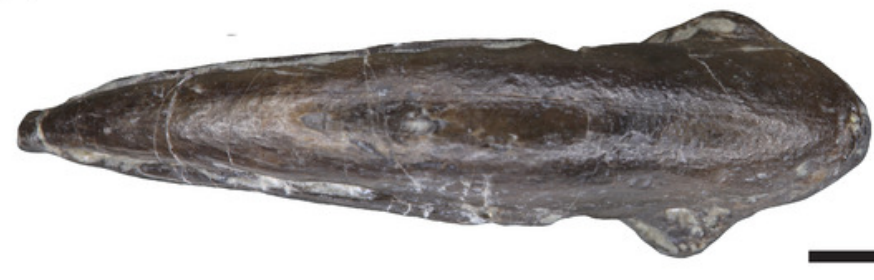

C

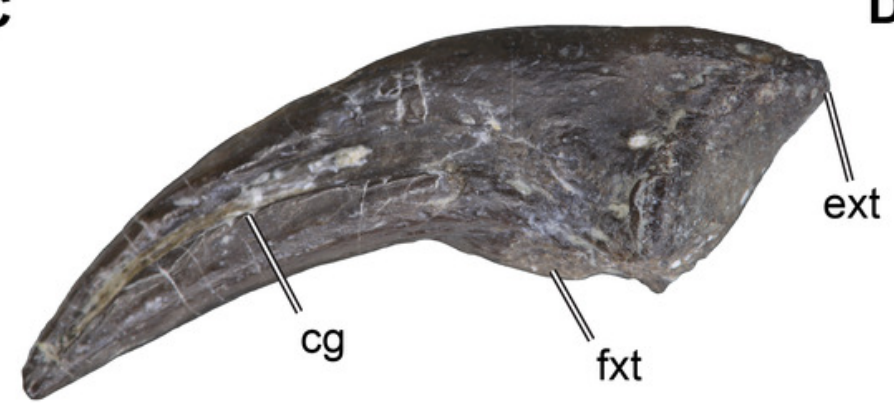

E
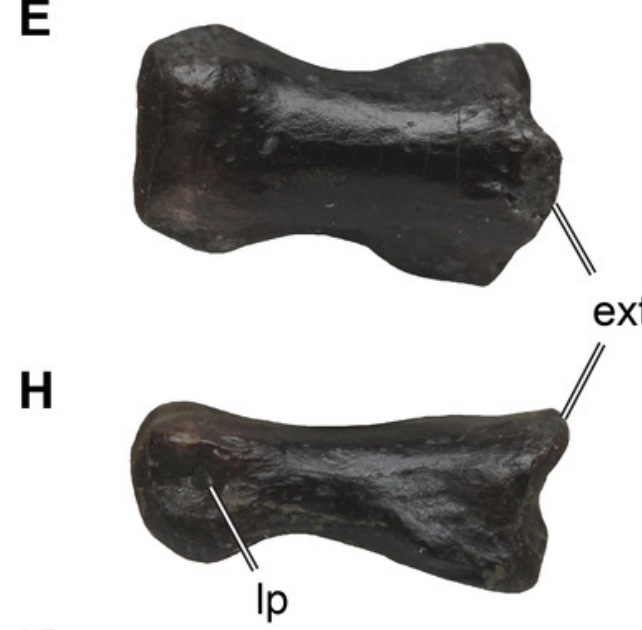

K

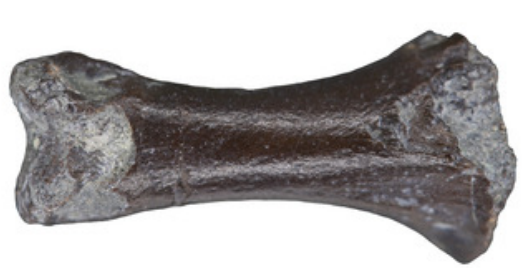

$\mathbf{N}$

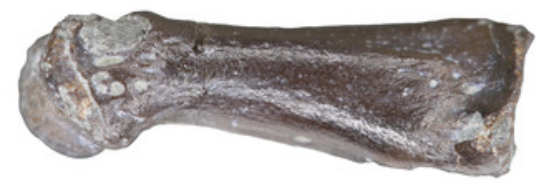

F

L

0
B

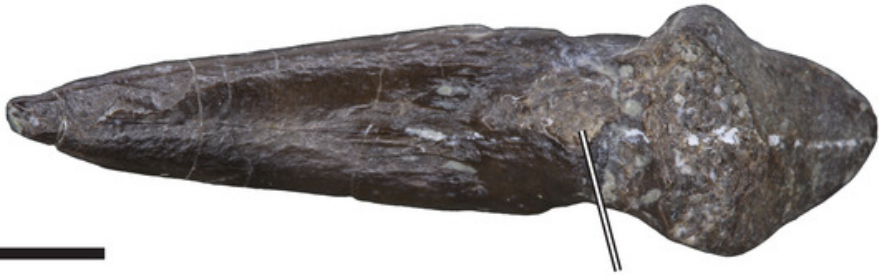

fxt

\section{D}
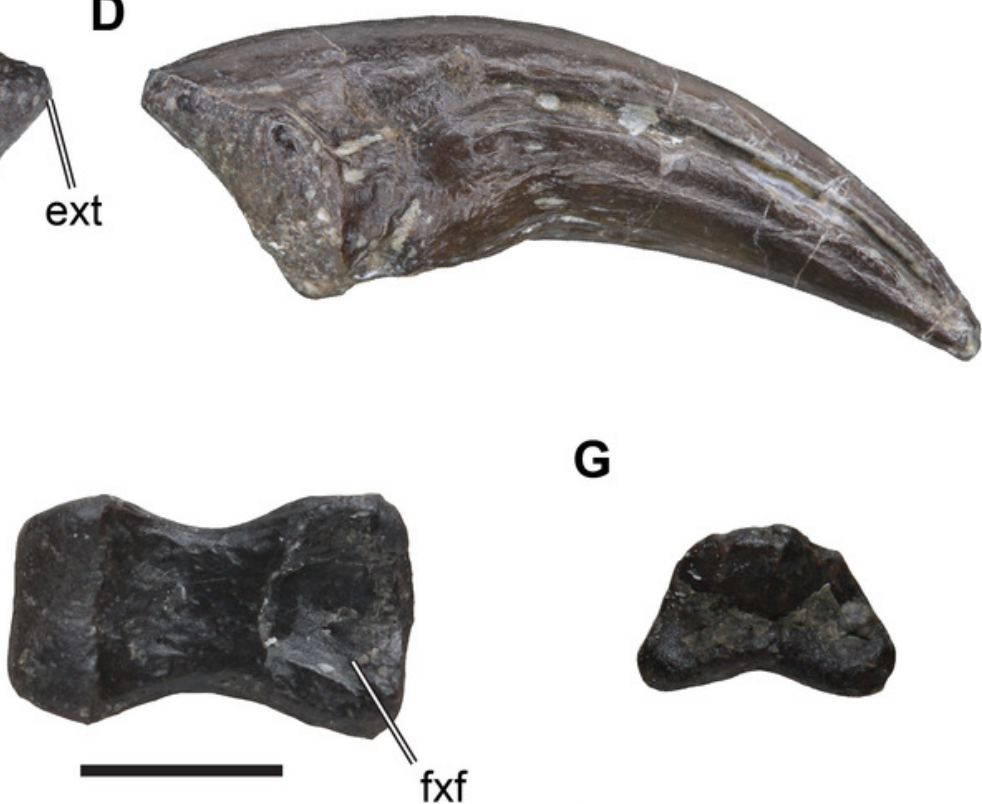

G
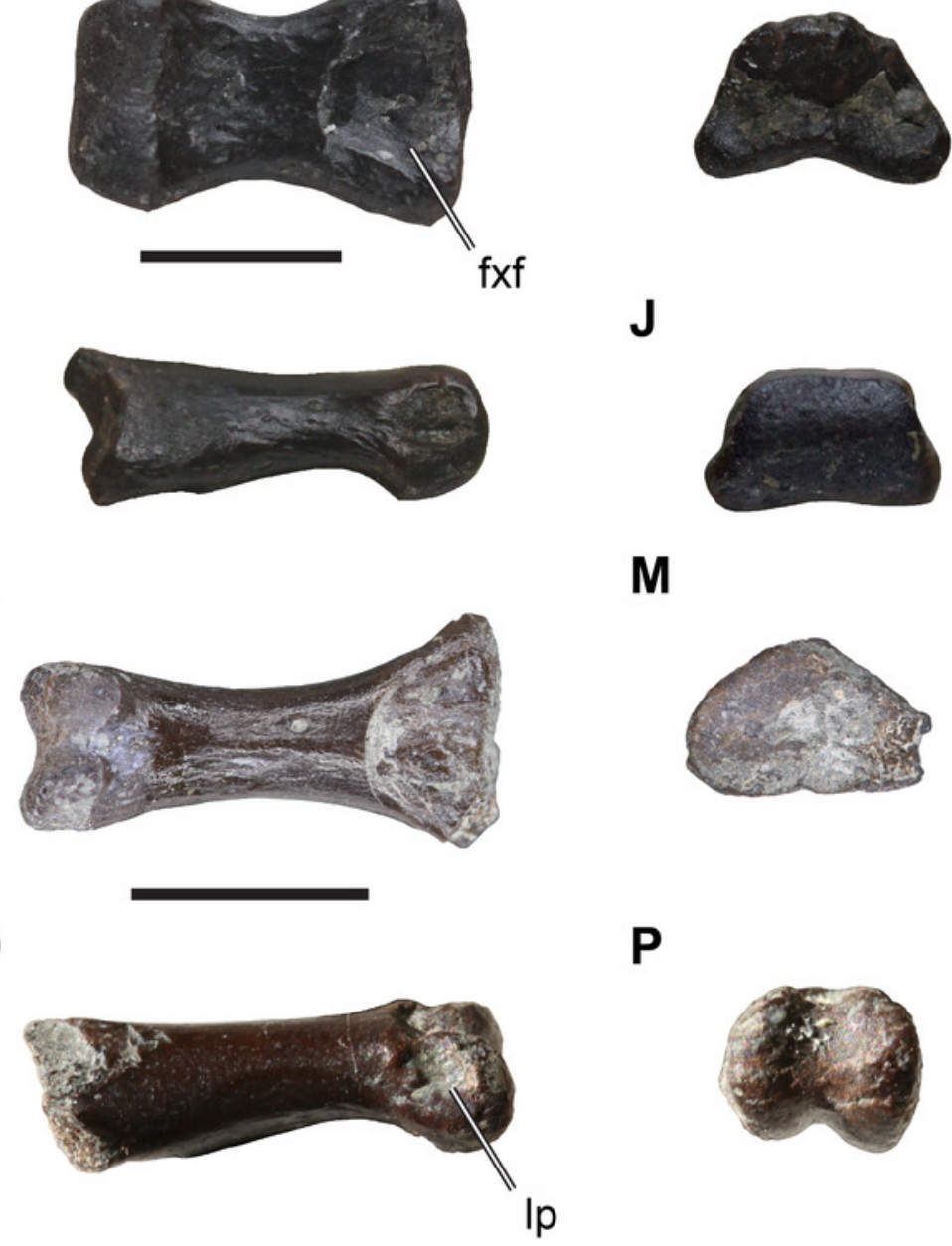

M
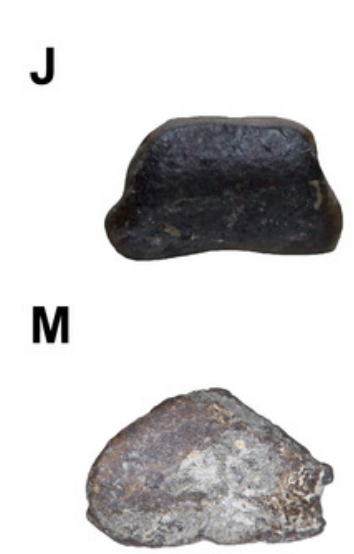

P

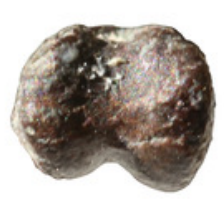




\section{Figure 3}

Isolated theropoda axial elements from the Langenberg Quarry.

DfMMh/FV/776, chevron, in (A) anterior view, (B) left lateral view, (C) posterior view, (D) right lateral view, (E) anterodorsal view on proximal articular surface. DfMMh/FV/105, distal caudal vertebra, in (F), ventral view, (G) dorsal view, $(H)$ anterior view, (I) posterior view, (J) left lateral view, (K) right lateral view. Abbreviations: ak, anterior keel; hc, hemal canal; poz, postzygapophysis. Scale bar in A-E equals $20 \mathrm{~mm}$, scale bar in F-K equals $10 \mathrm{~mm}$. 
A

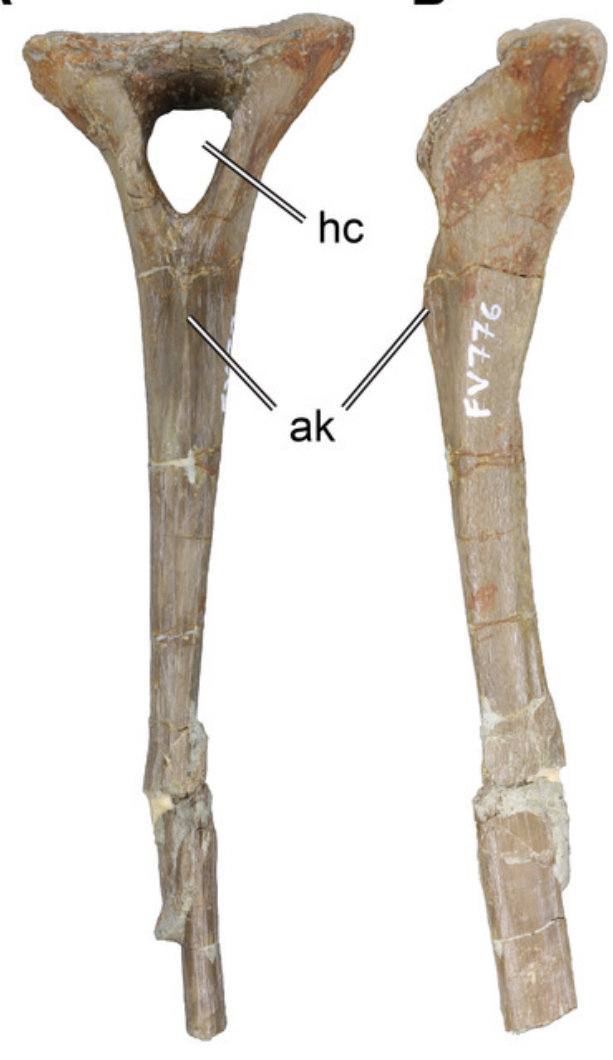

C

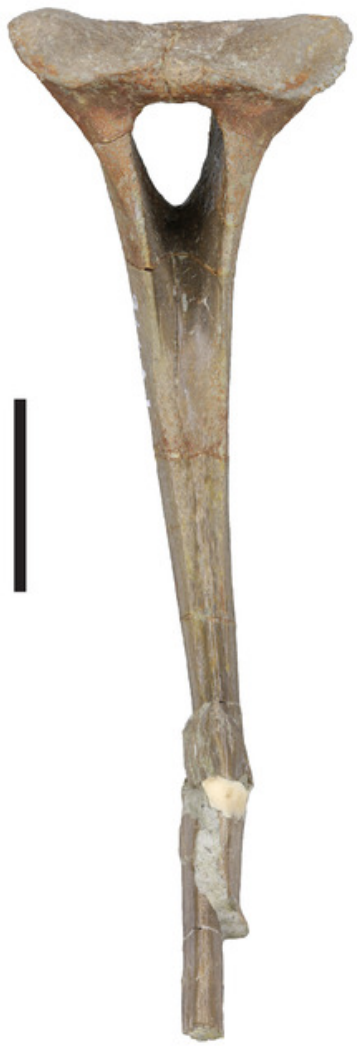

D $E$

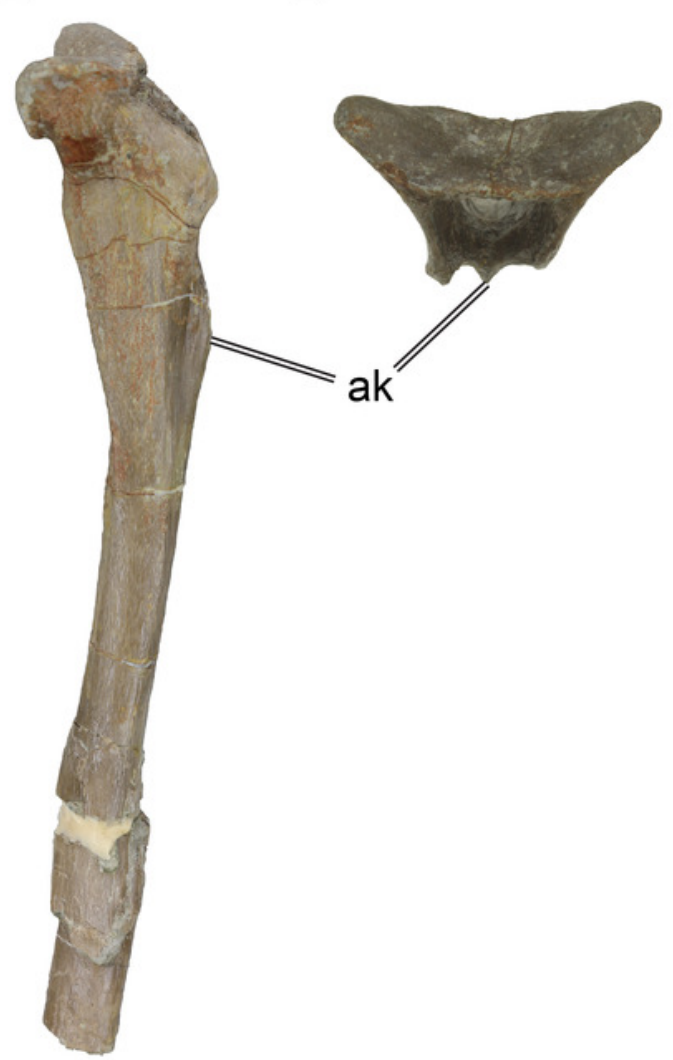

F

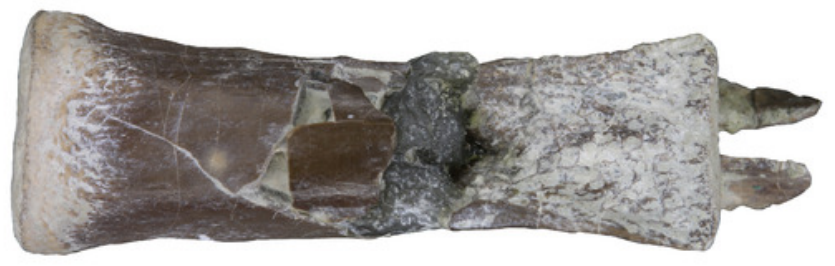

H

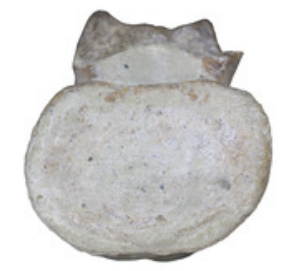

G
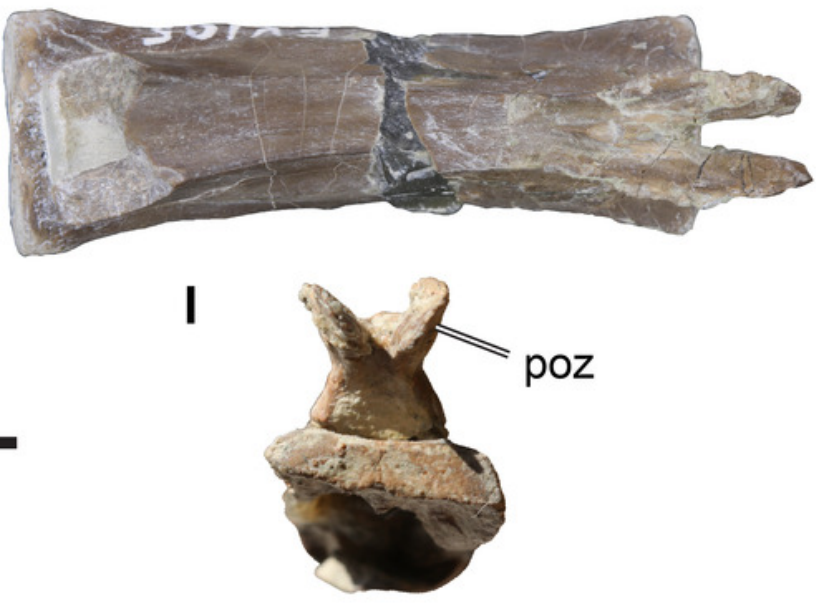

J

K

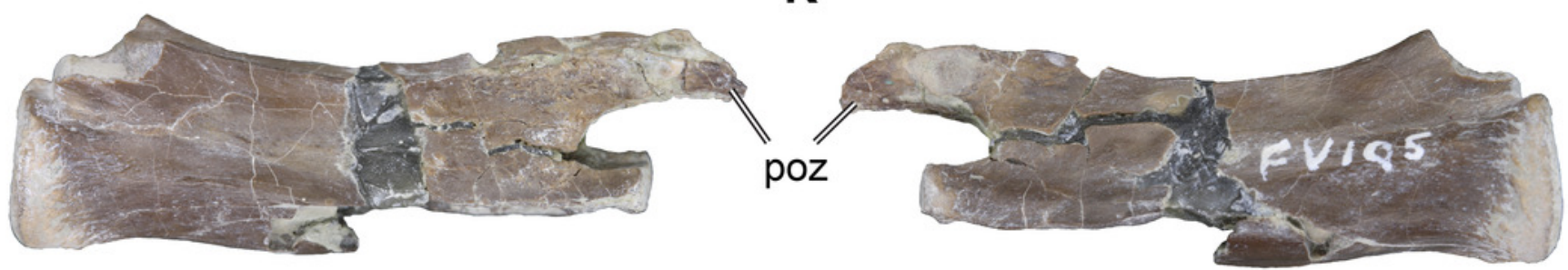




\section{Figure 4}

Isolated theropodan fibulae from the Langenberg Quarry.

$\mathrm{DfMMh} / \mathrm{FV} / 287$, left fibula in (A) anterior view, (B) medial view, (C) proximal view, (D)

posterior view, (E) medial view. DfMMh/FV3/19, partial right fibula in (F) anterior view, (G) lateral view, (H) proximal view, (I) posterior view, (J) medial view. Abbreviations: g, groove; $\mathrm{mf}$, medial fossa; pr, posterior ridge; tif, tubercle for the M. iliofibularis. All scale bars equal $20 \mathrm{~mm}$. 


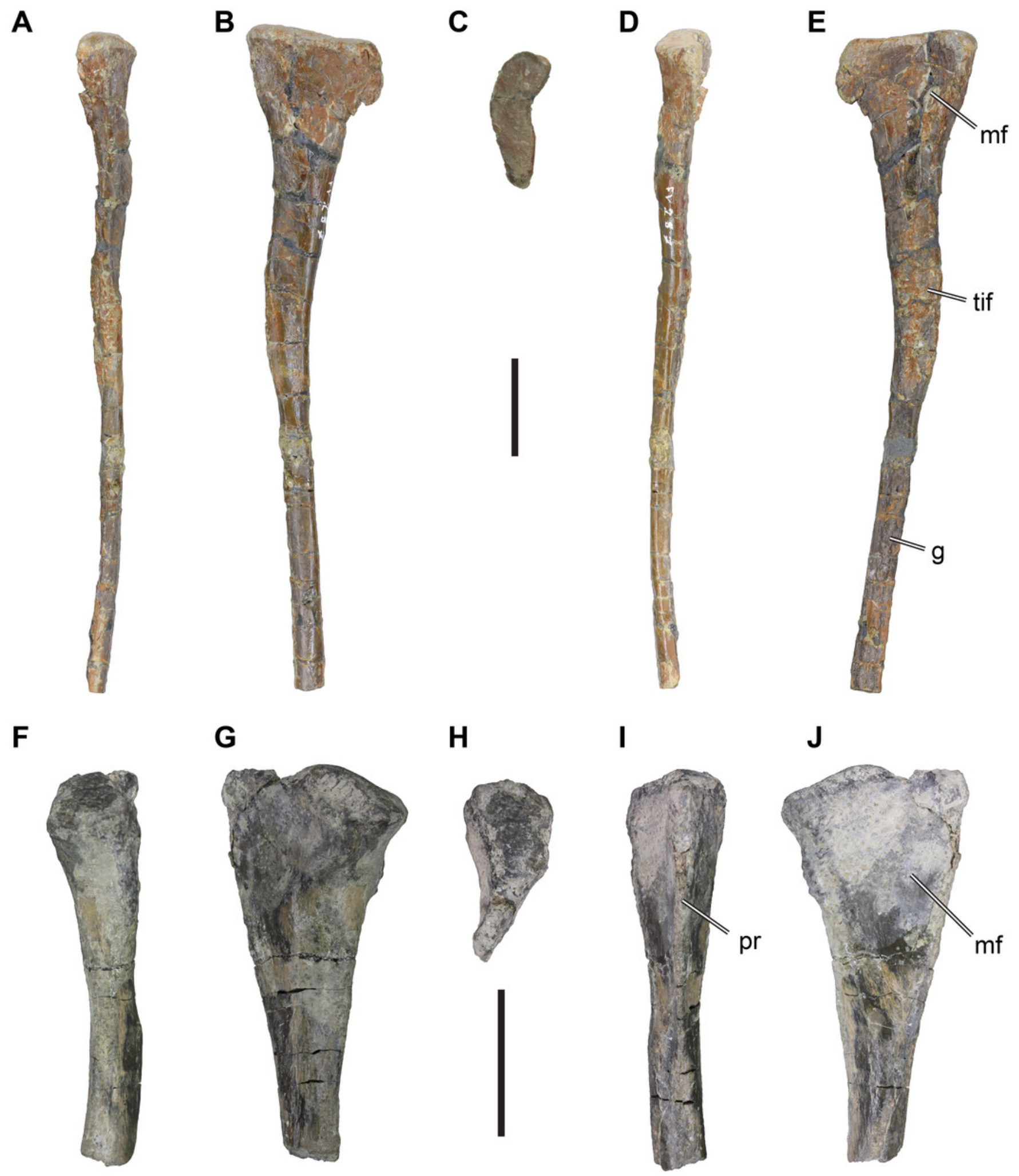

